\title{
Jornadas del Comité de Nefropatía de la Sociedad Argentina de Diabetes Actualización de cirugía bariátrica en paciente con diabetes y enfermedad renal. Parte 2
}

\author{
Conference of the Nephropathy Committee \\ of the Argentine Diabetes Society \\ Bariatric surgery update in a patient with diabetes and kidney disease. Part 2
}

\section{Comité de Nefropatía Diabética de la Sociedad Argentina de Diabetes}

Expertos: Alicia Elbert ${ }^{1}$, Susana Gutt ${ }^{2}$, Estrella Menéndez ${ }^{3}$

Participantes (en orden alfabético): María Florencia Aranguren ${ }^{4}$, Bárbara Arinovich ${ }^{5}$, Teresa Bensusan ${ }^{6}$, Guillermo De’'Marziani' ${ }^{7}$, Guillermo Dieuzeide ${ }^{8}$, Gabriela Medek ${ }^{9}$, Liliana Miriam Obregon ${ }^{10}$, María José Pomares ${ }^{11}$, Jimena Soutelo ${ }^{12}$, Fabiana Vázquez ${ }^{13}$, Gloria Viñes ${ }^{14}$, Mariela Volta ${ }^{15}$

Coordinadoras: Fabiana Dávila ${ }^{16}$, Yanina Castaño ${ }^{17}$

En memoria de Mariela Canda ${ }^{18}$

\section{RESUMEN}

La prevalencia de obesidad y diabetes mellitus se asocia al desarrollo de enfermedad renal crónica y estadios terminales de la misma. En individuos con obesidad se produce un mecanismo de hiperfiltración, probablemente compensatorio para satisfacer la alta demanda metabólica asociada al aumento del peso corporal, con la presencia de proteinuria en individuos sin enfermedad renal. La histopatología muestra una glomeruloesclerosis focal y segmentaria relacionada con la obesidad en un marco de glomerulomegalia. La cirugía metabólica es el medio más efectivo para obtener una pérdida de peso sustancial y persistente. Se ha demostrado la superioridad de la cirugía sobre el tratamiento médico no solo para lograr un mejor control glucémico, sino también para la reducción de los factores de riesgo cardiovascular. Los mecanismos parecen extenderse más allá de la magnitud de la pérdida de peso e incluyen mejoras tanto en los perfiles de incretinas como en la secreción y la sensibilidad a la insulina.

El Comité de Nefropatía de la Sociedad Argentina de Diabetes realizó esta revisión sobre los mecanismos involucrados en la obesidad como causa de enfermedad renal o empeoramiento de la misma por diabetes, y los mecanismos a través de los cuales la cirugía bariátrica beneficiaría a los pacientes con diabetes y enfermedad renal crónica en todos los estadios de la misma, así como los controles pre y posquirúrgicos en este tipo de cirugías.

Palabras clave: obesidad; diabetes; cirugía bariátrica; cirugía metabólica; enfermedad renal crónica; glomerulopatía focal y segmentaria.

Revista de la Sociedad Argentina de Diabetes 2021; Vol. 55 (90-108)

\section{ABSTRACT}

The prevalence of obesity and diabetes mellitus are associated with the development of chronic kidney disease and its terminal stages. In individuals affected by obesity, a probably compensatory hyperfiltration mechanism occurs to satisfy the high metabolic demand associated with increased body weight; it is also associated with the presence and development of proteinuria in individuals without kidney disease. Histopathology shows obesity-related focal and segmental glomerulosclerosis in a setting of glomerulomegaly. Metabolic surgery is the most effective means of obtaining substantial and lasting weight loss. The superiority of surgery over medical treatment has been demonstrated only to achieve better glycemic control, as well as a reduction in cardiovascular risk factors. The mechanisms appear to extend beyond the magnitude of weight loss and include improvements in incretin profiles, insulin secretion, and insulin sensitivity.

The Nephropathy Committee of the Argentine Diabetes Society carried out this review on mechanisms involved in obesity as a cause of kidney disease or worsening of kidney disease due to diabetes, the mechanisms by which bariatric surgery would benefit patients with diabetes and kidney disease chronic and its terminal stages, the pre and post-surgical controls that should be performed by patients undergoing this type of surgery.

Key words: obesity; diabetes; bariatric surgery; metabolic surgery; chronic kidney disease; focal and segmental glomerulopathy. 
1 Médica especialista en Nefrología, especializada en Diabetes, Directora del Centro de Enfermedades Renales e Hipertensión Arterial (CEREHA S.A.), Ciudad Autónoma de Buenos Aires, Argentina

2 Médica especialista en Nutrición, Jefa de Sección Nutrición, Servicio de Clínica Médica, Hospital Italiano de Buenos Aires, Ciudad Autónoma de Buenos Aires, Argentina

3 Médica especialista en Nutrición, Servicio de Nutrición y Diabetes, Centro de Educación Médica e Investigaciones Clínicas "Norberto Quirno" (CEMIC), Ciudad Autónoma de Buenos Aires, Argentina

4 Médica especialista en Medicina Interna, especializada en Diabetes, Hospital de Clínicas José de San Martín, Ciudad Autónoma de Buenos Aires, Argentina

5 Médica especialista en Medicina Interna y Nutrición, Consultorios Privados Cabildo y Céspedes, Ciudad Autónoma de Buenos Aires, Argentina

6 Médica especialista en Medicina Interna, especializada en Diabetes, Centro Médico Cepem, Morón, Provincia de Buenos Aires, Argentina

7 Médico especialista en Medicina Interna, especialista en Nefrología y Magister en Diabetes, Centro de Enfermedades Renales e Hipertensión Arterial (CEREHA S.A.), Provincia de Buenos Aires, Argentina

8 Doctor en Medicina, Universidad de Buenos Aires (UBA), especialista en Endocrinología, Jefe del Servicio de Endocrinología y Diabetes, Hospital Nuestra Señora del Carmen, Chacabuco, Provincia de Buenos Aires, Argentina

9 Médica especialista en Medicina Interna, especializada en Diabetes, Medical Scientific Laison Novo Nordisk, Vicente López, Buenos Aires, Consultorio de Diabetes Sanatorio Finochietto, Ciudad Autónoma de Buenos Aires, Argentina

10 Médica especialista consultor en Endocrinología, Jefa de Sala del Área de Trasplante Renal Centro Único Coordinador de Ablación e Implante de la Provincia de Buenos Aires (CUCAIBA-CRAI Sur-HIGA), Hospital General San Martín de La Plata, Provincia de Buenos Aires, Argentina

11 Médica especialista en Nefrología y especializada en Diabetes, Hospital Penna, Consultorios del Centro de Enfermedades Renales e Hipertensión Arterial (CEREHA S.A.), Ciudad Autónoma de Buenos Aires, Argentina
12 Médica endocrinóloga, Universidad de Buenos Aires (UBA), especializada en Diabetes, Servicio de Endocrinología, Hospital Churruca Visca, Ciudad Autónoma de Buenos Aires, Argentina

13 Médica especialista en Nutrición, especializada en Diabetes, Servicio de Endocrinología, Hospital Británico, sede Vicente Lopéz, Provincia de Buenos Aires, Argentina

14 Médica especialista en Nutrición, especializada en Diabetes, Jefa del Servicio de Nutrición y Diabetes, Hospital Privado de Comunidad, Mar del Plata, Provincia de Buenos Aires, Argentina

15 Licenciada en Nutrición, Universidad de Buenos Aires (UBA), Ciudad Autónoma de Buenos Aires, Argentina

16 Médica especialista en Nutrición, Servicio de Diabetes, Hospital Universitario Austral, Pilar, Provincia de Buenos Aires, Argentina

17 Médica especialista en Nutrición, Magister en Diabetes, Coordinadora del Área de Diabetes del Centro de Diálisis CETRO (Centro de Estudios y Tratamiento Renal Olavarría), Provincia de Buenos Aires, Argentina

18 Médica especialista en Medicina Interna, especializada en Diabetes, Médica de Planta, Hospital de Rehabilitación Manuel Rocca, Gobierno de la Ciudad de Buenos Aires (GCBA), Ciudad Autónoma de Buenos Aires, Argentina

Contacto de la autora: Yanina Castaño

E-mail: casyanina@hotmail.com

Correspondencia: Moreno $24446^{\circ}$ "A" Olavarria (CP 7400),

Provincia de Buenos Aires, Argentina

Fecha de trabajo recibido: 18/02/21

Fecha de trabajo aceptado: 03/05/21

Conflictos de interés: la Dra. Susana Gutt declara haber recibido honorarios por consultoría, disertación y/o entrenamiento de disertantes de los laboratorios Novo Nordisk, Raffo y Bagó. La Dra. Fabiana Vázquez manifiesta haber recibido honorarios por consultoría, disertación y/o entrenamiento de disertantes de los laboratorios Novo Nordisk, Boehringer Ingelheim, AstraZeneca, Servier, Lilly y Merck. La Gloria Viñes declara haber recibido honorarios por consultoría, disertación y/o entrenamiento de disertantes de los laboratorios Servier, Boehringer Ingelheim, Novartis, Merck Sharp \& Dohme, Sanofi Aventis, Bayer y Novo Nordisk. El resto de los autores declara que no existe conflicto de interés.

\section{INTRODUCCIÓN}

La diabetes (DM) y la obesidad son dos patologías con muy alta prevalencia y ambas potencian la aparición de enfermedad renal. El objetivo de la Jornada del Comité de Nefropatía fue actualizar el tema de cirugía bariátrica (CB) en el paciente con DM y su impacto en la función renal.

En la primera parte de este documento desarrollamos los temas de epidemiología y fisiopatogenia incluyendo, además de los mecanismos hemodinámicos y hormonales, un tema de gran actualidad como el de microbiota intestinal y su relación con la obesidad, la DM y la enfermedad renal. Asimismo, en ese apartado se abordó el tema de CB, definición, indicaciones y efectos sobre el filtrado glomerular.

Esta segunda parte del manuscrito está dedicada al tratamiento alimentario y farmacológico, inclusive el tratamiento farmacológico poscirugía bariátrica. También se revisaron las complicaciones de la cirugía relacionadas con el riñón y, por último, se actualizó el tema de remisión de la DM poscirugía bariátrica. 


\section{Manejo nutricional pre y poscirugía bariátrica en pacientes con DM, con y sin enfermedad renal}

\section{Tratamiento nutricional prequirúrgico}

- Objetivos nutricionales: favorecer el descenso de peso previo a la cirugía, con la consecuente reducción del tejido adiposo visceral y del volumen hepático para facilitar la técnica quirúrgica; corregir las alteraciones metabólicas y de micronutrientes, y educar en la incorporación de hábitos saludables ${ }^{1,2}$.

Deben considerarse varios aspectos:

- Anamnesis: historia del proceso de ganancia de peso (edad de inicio de obesidad, tratamientos previos, peso máximo/mínimo, tiempo de permanencia en el peso adecuado). Pacientes con enfermedad renal crónica (ERC): estadificar la enfermedad renal y años en diálisis ${ }^{3}$.

- Valoración antropométrica: permitirá monitorear el descenso de peso poscirugía bariátrica (CB). Registrar en la primera entrevista: peso actual, talla, índice de masa corporal (IMC) inicial para calcular luego el porcentaje de exceso de IMC perdido (PEIMCP), peso esperable con IMC $=25 \mathrm{~kg} / \mathrm{m}^{2}, I M C$ esperable (IMCE) a los tres años de la cirugía, circunferencia de cintura y diámetro sagital ${ }^{4}$. Pacientes con ERC: el peso a considerar será aquel libre de edema (ajustar en aquellos pacientes con peso seco $<95 \%$ o $>115 \%$ del peso adecuado para la talla y edad). También son importantes los indicadores de masa muscular (circunferencia media muscular del brazo, test de fuerza) y grasa (pliegue tricipital).

- Evaluación bioquímica: rutina clínica, perfil lipídico y micronutrientes. En pacientes con ERC se agrega: prealbúmina, hierro, transferrina, TIBC (siglas en inglés de: capacidad total de unión de hierro), folato, cianocobalamina, vitamina D, hormona paratiroidea (PTH, por sus siglas en inglés), calcio, fósforo y potasio sérico².

De acuerdo a la American Diabetes Association (ADA), el descenso de peso del 5-10\% permite la reducción de la glucemia en ayunas y $\mathrm{HbA} 1 \mathrm{c}$, y facilita acercarse al objetivo glucémico pre-CB ${ }^{5}$. Sin embargo, los mejores resultados posquirúrgicos se obtienen con descensos de al menos $8 \%$ del peso inicial y entre un 5 a un $10 \%$ del exceso de peso, siendo ésta la recomendación del Consenso Argentino de Nutrición para Cirugía Bariátrica ${ }^{4,6}$.

Para lograr este descenso, no existe una recomendación sobre el inicio del plan alimentario hipocalórico que varía entre seis a 12 semanas previas a la cirugía y aporta 1.200-1.500 kcal/día (kcal/d) para las mujeres y $1.500-1.800 \mathrm{kcal} / \mathrm{d}$ para los hombres, según la recomendación de la ADA ${ }^{5,6}$. Existe consenso respecto de la dieta inmediatamente anterior a la cirugía, la cual debe ser muy baja en calorías (DMBC): $\leq 800 \mathrm{kcal} / \mathrm{d}$, puede comenzar dos a cuatro semanas previas a la cirugía y debe monitorearse cuidadosamente $e^{4,7}$ para lograr la reducción del $80 \%$ del volumen hepático en las dos primeras semanas (no se justifica prolongarla) ${ }^{7}$. Tanto el consenso nacional como los internacionales proponen que la DMBC tenga una consistencia líquida con inicio, según criterio médico, entre uno a 14 días previos ${ }^{4,8,9}$

Actualmente no existe una recomendación sobre la distribución de macronutrientes, pero se conocen los beneficios de las dietas bajas en hidratos de carbono sobre aquellas bajas en grasas ${ }^{8}$. Sin embargo, las primeras no se recomiendan en ERC ${ }^{5,6}$. En la DMBC se sugiere un $25-30 \%$ de proteínas y mínimo $130 \mathrm{~g}$ de hidratos de carbono $(\mathrm{HC}), 7-10 \mathrm{~g} / \mathrm{d}$ de grasas seleccionadas para garantizar el aporte de ácidos grasos esenciales y $10 \mathrm{~g}$ de fibra soluble, con adecuada hidratación de al menos 2 litros/día 2,4,7.

En pacientes con ERC, la ADA sugiere mantener la recomendación proteica $0,8 \mathrm{~g} / \mathrm{kg}$ de peso/d. Sin embargo, en pacientes con diabetes mellitus tipo 2 (DM2), sin enfermedad renal, varios estudios demostraron que ingestas levemente superiores (20-30\%) aumentarían la saciedad con buen control metabólico 6 .

Se necesita la suplementación vitamínica y mineral prequirúrgica para cubrir el $100 \%$ de las ingestas diarias recomendadas (IDR). La American Society for Metabolic and Bariatric Surgery actualizó en 2017 las recomendaciones de micronutrientes e incorporó al cobre como un mineral que debe también tenerse en cuenta por su relación con el zinc ${ }^{1}$ (Tabla 1).

\section{Tratamiento nutricional posquirúrgico}

- Objetivos nutricionales: asegurar un adecuado aporte energético y nutricional para la recuperación posquirúrgica, preservar la masa magra durante la mayor pérdida de peso, y minimizar el reflujo y la saciedad precoz para maximizar la pérdida de peso ${ }^{4,7}$.

Debido a la reducción de la capacidad gástrica, se modifica la consistencia para evitar o minimizar las náuseas y regurgitación. En las primeras 24 horas (h) se inicia una dieta líquida clara, baja en azúcares, que se irá progresando gradualmente a alimentos suaves y cremosos hasta llegar a sólidos a las dos a cuatro semanas ${ }^{4,10}$. Es importante 
garantizar el estado de hidratación con la ingesta de al menos $1.500 \mathrm{ml} / \mathrm{d}$ desde el primer día con pequeños sorbos ( $30 \mathrm{ml} /$ toma). Al incorporar alimentos semisólidos, los líquidos deben estar alejados: 15 minutos antes y 30 minutos después progresando de a 60-100 ml/porción hasta lograr una taza/porción ${ }^{10}$. Aún en los pacientes con ERC avanzada, es mayor la preocupación por la deshidratación posquirúrgica y mayor deterioro renal que por el exceso de líquidos, especialmente si se intercurre con vómitos. Por este motivo, para evitar la sobrecarga de líquidos y la ganancia de peso interdialítica, se recomienda adicionar $500 \mathrm{ml}$ al volumen urinario diario ${ }^{3}$. En ERC E 1-3 y en pacientes trasplantados no suele indicarse la restricción hídrica, por lo que pueden seguirse los lineamientos para la cirugía metabólica $(\mathrm{CM})^{3}$.

El valor energético al inicio no supera las $1.000 \mathrm{kcal} / \mathrm{d}$ y aumenta paulatinamente a $1.200-1.400 \mathrm{kcal} / \mathrm{d}$ a partir de los seis a 12 meses, según tolerancia ${ }^{2,4}$.

El consumo adecuado de proteína es muy importante en esta etapa porque reduce la pérdida de masa magra ante la pérdida rápida de peso. Sin embargo, la ingesta proteica poscirugía suele reducirse por mayor intolerancia gástrica ${ }^{10}$. Las guías actuales recomiendan un aporte mínimo de $60 \mathrm{~g} / \mathrm{d}$ ó 1.1-1,5 g/kg peso ideal/d. El consumo de suplementos líquidos proteicos de hasta $30 \mathrm{~g} / \mathrm{d}$ puede facilitar el aporte proteico recomendado (de elección aquellos con proteínas de suero con alto contenido en leucina que permite mantener la masa magra 2,8,10. Entre los alimentos con alto contenido de leucina se encuentran los productos derivados de soja, huevos, carnes, lentejas y quesos de pasta dura ${ }^{8}$. A partir del año posoperatorio, se recomienda alcanzar $100 \mathrm{~g}$ de proteínas/d o el $25 \%$ del valor calórico total (VCT) ${ }^{4}$.

En ERC, para prevenir la desnutrición calórica proteica, se recomienda: 0,8-1 $\mathrm{g} / \mathrm{kg}$ ideal $/ \mathrm{d}$ para $\mathrm{E}$ 3-5 sin hemodiálisis, $\geq 1,2 \mathrm{~g} / \mathrm{kg}$ peso seco ideal/d en hemodiálisis $y \geq 1,1 \mathrm{~g} / \mathrm{kg}$ peso ideal $/ \mathrm{d}$ en pacientes trasplantados, según el funcionamiento del injerto. El $50 \%$ debe ser de alto valor biológico ${ }^{3}$.

Se aconseja un aporte mínimo de $150 \mathrm{~g} / \mathrm{d}$ de HC complejos y evitar azúcares simples que favorecerían el síndrome de dumping y el 25-30\% VCT en grasas, aumentando el aporte de los ácidos grasos de cadena larga n-3 (ácido eicosapentaenoico -EPA- y docosahexaenoico -DHA-) y n-3 alfa linolénico (ALA). El aporte de fibra será a expensas de la fibra soluble ${ }^{3,8}$. El aporte de HC comienza con leche, yogur y bebidas de soja. Si bien la bibliografía consultada no manifiesta controversias con estos alimentos en los pacientes con ERC avanzada, debería controlarse el fósforo sérico y adecuar el consumo de los mismos si estuviese elevado.

La progresión hacia HC sólidos es lenta e incluye verduras y frutas, legumbres, arroz, pastas y pan. Una situación similar se plantea en este caso con el control del potasio. La deficiencia de vitaminas y minerales es un problema frecuente pos$\mathrm{CB}$, no solo por la técnica quirúrgica sino también por la falta de adherencia en la toma de la suplementación vitamínico-mineral y en la densidad de nutrientes de las comidas $^{10}$. Las recomendaciones para los pacientes con CB y enfermedad renal sometidos a CM se describen en las Tablas 2 y 3.

- Vitamina A: en ERC, la administración excesiva debe ser cautelosa porque podría tener efectos tóxicos, y se encontró correlación negativa entre el retinol plasmático y el filtrado glomerular (FG). Por este motivo, no se recomienda su suplementación en ERC, excepto que la ingesta sea menor a la IDR, se suplementará según la IDR (3.000 UI/ $900 \mathrm{mcg} / \mathrm{d}$ hombres y $2.330 \mathrm{Ul} / 700 \mathrm{mcg} / \mathrm{d}$ mujer), con la misma dosis en hemodiálisis ${ }^{3}$.

- Vitamina E: los requerimientos pos-CM no difieren con o sin $\mathrm{ERC}^{3}$.

- Vitamina K: si bien suele haber deficiencia en E 3-5 de la ERC, la evidencia actual indica que la IDR es igual que sin ERC $(120 \mathrm{mcg} / \mathrm{d}$ hombre y $90 \mathrm{mcg} / \mathrm{d}$ mujer $)^{3}$.

- Vitamina D y calcio (Ca): la suplementación se necesita en ERC para preservar la densidad mineral ósea, pero es controvertida la dosis de suplementación para evitar el balance positivo de calcio. En ERC moderada/avanzada se sugiere aportar 800-1.000 mg/d de Ca provenientes de alimentos y suplementos, y aporte de vitamina $D^{3}$.

- Fósforo: si bien se recomienda una ingesta $<800 \mathrm{mg} / \mathrm{d}$ para los ERC E 3-5, cuando existe riesgo de malnutrición calórica-proteica o en hemodiálisis, la restricción proteica y de fósforo podría no ser beneficiosa. Se recomienda enfatizar el control de la ingesta de fósforo inorgánico (Pi) por su mayor biodisponibilidad y la reducción de alimentos procesados por su contenido en aditivos ricos en $\mathrm{Pi}^{3}$.

- Potasio: el control de la ingesta de potasio se indica en los casos de hiperkalemia ${ }^{3}$.

- Ácido fólico y vitamina B12: ambos se suplementan en forma rutinaria pos-CB ${ }^{3}$.

- Hierro: es muy prevalente la deficiencia debido a la técnica quirúrgica y a la predisposición 
inherente a la ERC. La suplementación se indica hasta lograr el $20 \%$ de saturación de la transferrina y $>100 \mathrm{ng} / \mathrm{ml}$ de ferritina sérica en pacientes que no dializan o $>200 \mathrm{ng} / \mathrm{ml}$ en diálisis. La suplementación de rutina puede ser insuficiente, siendo necesaria la repleción intravenosa ${ }^{3}$.

- Vitamina C: controlar su aporte en aquellos pacientes que hayan presentado cálculos de oxalato de calcio secundarios al bypass gástrico en $Y$ de Roux
(BGYR). La recomendación en ERC es igual a la IDR ${ }^{3}$.

El protocolo de suplementación vitamínica y mineral pos-CM incluye: hierro, ácido fólico, zinc, cobre, selenio, vitamina $\mathrm{C}$, tiamina y vitaminas liposolubles $(A, D, E, K)$. El Primer Consenso Argentino de CM también recomienda la suplementación con biotina $2,5 \mathrm{mg} / \mathrm{día}^{2}$. En los pacientes con ERC, por su mayor riesgo de toxicidad por acumulación, deben monitorearse estos micronutrientes de forma más rigurosa ${ }^{3}$.

\begin{tabular}{|c|c|c|}
\hline Micronutriente & \% Deficiencia precirugía & \% Deficiencia poscirugía \\
\hline Tiamina & Hasta $29 \%$ & $<1 \%$ hasta $49 \%$ y según el tipo de cirugía y el tiempo desde la misma \\
\hline B12 & $\begin{array}{l}2-18 \% \text { en pacientes con obesidad y } 6-30 \% \text { en aquellos } \\
\text { medicados con inhibidores de la bomba de protones }\end{array}$ & $\begin{array}{l}\text { Se manifiesta a los } 2-5 \text { años } \\
<20 \% \text { BGYR y GVM }\end{array}$ \\
\hline Ácido fólico & Hasta $54 \%$ en pacientes con obesidad & Hasta $65 \%$ luego de CM \\
\hline Hierro & Hasta $45 \%$ en pacientes con obesidad & $\begin{array}{l}\text { Desde los tres meses posquirúrgicos hasta los } 10 \text { años pos-CM } \\
\text { GVM } 18 \% \text {, BGYR } 20-55 \%\end{array}$ \\
\hline Vitamina D y calcio & Hasta $90 \%$ en pacientes con obesidad & Hasta $100 \%$ poscirugía bariátrica \\
\hline $\begin{array}{l}\text { Vitaminas liposolubles } \\
(\mathrm{A}, \mathrm{E}, \mathrm{K})\end{array}$ & $\begin{array}{l}\text { Vitamina A: hasta } 14 \% \\
\text { Vitamina E: } 2,2 \% \\
\text { No existe evidencia de déficit de vitamina K }\end{array}$ & $\begin{array}{l}\text { Vitamina A: hasta un } 70 \% \text { de los pacientes con BGYR dentro de los } \\
\text { cuatro años poscirugía } \\
\text { La deficiencia de vitaminas E y K es poco frecuente }\end{array}$ \\
\hline Zinc & $\begin{array}{l}24-28 \% \text { en los pacientes en general sometidos a } \\
\text { procedimientos bariátricos }\end{array}$ & Hasta $40 \%$ pos-BGYR, $19 \%$ pos-GVM \\
\hline Cobre & $\begin{array}{l}\text { Hasta el } 70 \% \text { en las mujeres previo a derivación } \\
\text { biliopancreática }\end{array}$ & 10-20\% pos-BGYR. Se reportó solo un caso pos-GVM \\
\hline
\end{tabular}

Adaptado de: Parrott J, et al.?

BGYR: bypass gástrico en Y de Roux; GVM: gastrectomía vertical en manga; CM: cirugía metabólica.

Tabla 1: Prevalencia de deficiencia de micronutrientes prequirúrgica y posquirúrgica.

\begin{tabular}{|c|c|c|}
\hline \multirow[t]{2}{*}{ Micronutriente } & \multicolumn{2}{|c|}{ Suplementación para prevenir deficiencia } \\
\hline & DM2 & ERC \\
\hline Hierro & \multicolumn{2}{|c|}{ 45-60 mg/día en MVM. Consumirlos lejos de los suplementos de calcio } \\
\hline B12 & $\begin{array}{l}\text { Oral: } 350-500 \mu \mathrm{g} / \mathrm{d} \\
\text { IM o SC: } 1.000 \mu \mathrm{g} / \text { mes o } 3.000 \mu \mathrm{g} \text { cada seis meses } \\
\text { Intranasal: } 500 \mu \mathrm{g} / \mathrm{semana}\end{array}$ & Sublingual: $350-500 \mu \mathrm{g} / \mathrm{d}$ \\
\hline Ácido fólico & $\begin{array}{l}400-800 \mu \mathrm{g} / \mathrm{d} \text { y mujeres en edad fértil } \\
800-1.000 \mu \mathrm{g} / \mathrm{d} \text { en MVM }\end{array}$ & $\begin{array}{l}\text { ERC y trasplante: } 400-800 \mu \mathrm{g} / \mathrm{d} \\
\text { HD: } 1 \mathrm{mg} / \mathrm{d}\end{array}$ \\
\hline $\begin{array}{l}\text { Calcio } \\
\text { (preferentemente citrato) }\end{array}$ & $\begin{array}{l}\text { Calcio GVM, BGYR: } 1.200-1.500 \mathrm{mg} / \mathrm{d} \\
\text { (Guías Europeas: } 1.200-2.000 \mathrm{mg} / \mathrm{d} \text { ) }\end{array}$ & $\begin{array}{l}\text { ERC: } 800-1.000 \mathrm{mg} / \mathrm{d} \text { con los alimentos. } \\
\text { HD: }<800 \mathrm{mg} / \mathrm{d} \text { con los alimentos. } \\
\text { Trasplante: } 1.200-1.500 \mathrm{mg} \text { con los alimentos y suplementos }\end{array}$ \\
\hline Vitamina D & \multicolumn{2}{|c|}{ Vitamina D 3.000Ul/día } \\
\hline Vitamina A & BGYR y BG: $10.000 \mathrm{U} / \mathrm{d}$ en MVM & $\begin{array}{l}\text { ERC, HD y trasplante: } \\
\text { Hombres: }<3.000 \mathrm{UI} / \mathrm{d} \\
\text { Mujeres: }<2.330 \mathrm{UI} / \mathrm{d} \\
\end{array}$ \\
\hline Vitamina K & BGYR y BG: $120 \mu \mathrm{g} / \mathrm{d}$ en MVM & $\begin{array}{l}\text { ERC, HD y trasplante: } \\
\text { Hombres: }<120 \mu \mathrm{g} / \mathrm{d} \\
\text { Mujeres: }<90 \mu \mathrm{g} / \mathrm{d}\end{array}$ \\
\hline Vitamina $\mathrm{E}$ & $15 \mathrm{mg} / \mathrm{d}$ en MVM & $<15 \mathrm{mg} / \mathrm{d}$ \\
\hline Tiamina & 50- $100 \mathrm{mg} / \mathrm{d}$ en MVM & $\geq 12 \mathrm{mg} / \mathrm{d}$ \\
\hline Zinc & $\begin{array}{l}\text { GVM: } 8-11 \mathrm{mg} / \mathrm{d} \\
\text { BGYR: } 8-22 \mathrm{mg} / \mathrm{d} \text { en MVM }\end{array}$ & $\begin{array}{l}\text { ERC, HD y trasplante: } \\
\text { GVM: } 8-11 \mathrm{mg} / \mathrm{d} \\
\text { BGYR: } 8-22 \mathrm{mg} / \mathrm{d}\end{array}$ \\
\hline Cobre & $\begin{array}{l}\text { BGYR: } 2 \mathrm{mg} / \mathrm{día} \text { en MVM } \\
\text { GVM:1 mg/d }\end{array}$ & $\begin{array}{l}\text { ERC, HD y trasplante: } \\
\text { GVM: } 1 \mathrm{mg} / \mathrm{d} \\
\text { BGYR: } 1-2 \mathrm{mg} / \mathrm{d}\end{array}$ \\
\hline
\end{tabular}

Adaptado de: Parrott J, et al. ${ }^{1}$; Aguirre A, et al. ${ }^{2}$; Palacio AC, et al. ${ }^{10}$.

DM2: diabetes mellitus tipo 2; ERC: enfermedad renal crónica; MVM: multivitamínico y mineral; IM: intramuscular; SC: subcutánea; HD: hemodiálisis; BG: banda gástrica; GVM: gastrectomía vertical en manga; BGYR: bypass gástrico en Y de Roux.

Tabla 2: Recomendación de la suplementación posquirúrgica para la prevención de la deficiencia de micronutrientes en pacientes con DM2 y ERC. 


\begin{tabular}{|c|c|c|}
\hline \multirow[t]{2}{*}{ Micronutriente } & \multicolumn{2}{|c|}{ Suplementación para tratar deficiencia } \\
\hline & DM2 & ERC \\
\hline Hierro & Oral: $150-200 \mathrm{mg} / \mathrm{d}$ hasta $300 \mathrm{mg} \mathrm{2-3} \mathrm{veces/d}$ & $\begin{array}{l}\text { ERC: oral: } 200 \mathrm{mg} / \mathrm{d} \text { durante } 1-3 \text { meses } \\
\text { HD: IV de acuerdo a deficiencia } \\
\text { Discontinuar con } \% \text { SAT }>30 \% \text { y ferritina sérica }>500 \mathrm{ng} / \mathrm{ml}\end{array}$ \\
\hline B12 & $1.000 \mu \mathrm{g} / \mathrm{d}$ & $\begin{array}{l}\text { Sublingual: } 1.000-2.000 \mu \mathrm{g} / \mathrm{d} \\
\text { IM: } 1.000 \mu \mathrm{g} / \mathrm{semana}\end{array}$ \\
\hline Ácido fólico & \multicolumn{2}{|c|}{$1.000 \mu \mathrm{g} / \mathrm{d}$} \\
\hline Calcio & $1.200-1.500 \mathrm{mg} / \mathrm{d}$ & Sin datos \\
\hline Vitamina D & \multicolumn{2}{|c|}{$\begin{array}{c}\text { Vitamina D3 3.000- 6.000IU/d o } 50.000 \text { IU vitamina D2 1-3 veces/semana } \\
\text { Continuar con terapia de mantenimiento }\end{array}$} \\
\hline Tiamina & \multicolumn{2}{|c|}{$\begin{array}{l}\text { Oral: } 100 \mathrm{mg} \text { 2-3 veces/d hasta resolución de los síntomas } \\
\text { IV: } 200 \mathrm{mg} 3 \text { veces/d a } 500 \mathrm{mg} 1-2 \text { veces/d durante } 3 \text { a } 5 \text { días, continuar con } 250 \mathrm{mg} / \mathrm{d} \text { durante } 3-5 \mathrm{~d} \\
\text { o hasta resolución de los síntomas. Luego considerar continuar con } 100 \mathrm{mg} / \mathrm{d} \text { en forma oral } \\
\text { IM: } 250 \mathrm{mg} / \mathrm{d} \text { durante } 3-5 \text { días o } 100-250 \mathrm{mg} / \mathrm{mes}\end{array}$} \\
\hline Magnesio & Sin datos & $300 \mathrm{mg} / \mathrm{d}$ (citrato) \\
\hline
\end{tabular}

Adaptado de: Parrott J, et al. ${ }^{1}$; Aguirre A, et al. ${ }^{2}$; Palacio AC, et al. ${ }^{10}$.

DM2: diabetes mellitus tipo 2; ERC: enfermedad renal crónica; MVM: multivitamínico y mineral; IM: intramuscular; SC: subcutánea; HD: hemodiálisis; IV: intravenoso; \%SAT: porcentaje de saturación de la transferrina.

Tabla 3: Recomendación de la suplementación posquirúrgica para el tratamiento de la deficiencia de micronutrientes en pacientes DM2 y en ERC.

\section{BIBLIOGRAFÍA}

1. Parrott J, Frank L, Rabena R, et al. American Society for Metabolic and Bariatric Surgery Integrated Health Nutritional Guidelines for the surgical weight loss patient 2016 Update: Micronutrients. Surg Obes Relat Dis 2017; 13(5):727-741.

2. Ben-Porat $T$, Weiss-Sadan $A$, Rottenstreiche $A$, et al. Nutritional management for chronic kidney disease patients who undergo bariatric surgery: a narrative review. Adv Nutr 2019; 10(1):122-132.

3. Aguirre-Ackermann M, Alva O, Álvarez MG, et al. Primer Consenso Argentino de Cirugía Metabólica 2015. Revista de la Sociedad Argentina de Diabetes 2015; 49(3): 95-110.

4. Pampillon $\mathrm{N}$, et al. Consenso Argentino de Nutrición en Cirugía Bariátrica. Actualización en Nutrición 2011; 12(2):98-141.

5. American Diabetes Association. Obesity management for the treatment of type 2 diabetes: Standards of Medical Care in Diabetes 2019. Diabetes Care 2019; 42 (Suppl.1):S81-S89.
6. American Diabetes Association. Lifestyle management: Standards of Medical Care in Diabetes 2019. Diabetes Care 2019; 42(Suppl.1):S46-S60.

7. Sivakumar J. Nutritional management of surgical patients in the peri-operative. J Obes Eat Disord 2018; 4:1. DOI: $10.21767 / 2471-8203.100033$

8. Sherf Dagan S, Goldenshluger A, Globus I, et al. Nutritional recommendations for adult bariatric surgery patients: clinical practice. Adv Nutr 2017; 15(2):382-394.

9. Palacio AC, Vargas $P$, Ghiardo D, et al. Primer consenso chileno de nutricionistas en cirugía bariátrica. Rev Chil Nutr 2019; 46(1):64-75.

10. Busetto L, Dicker D, Azran C, et al. Practical recommendations of the obesity management task force of the European Association for the Study of Obesity for the Post-Bariatric Surgery Medical Management. Obes Facts 2017; 10(6):597-632.

\section{Manejo farmacológico de los pacientes con DM pre y pos-CB}

Los pacientes con DM con enfermedad renal que se someterán a $\mathrm{CB}$ deben tener un estricto control metabólico en el período pre y periquirúrgico, ya que esta cirugía puede modificar bruscamente la sensibilidad a la insulina y generar hipoglucemias en pacientes sin eventos previos. La dieta muy baja en calorías, que se realiza los días previos, facilita la preparación del paciente; además quienes estén bajo tratamiento farmacológico para su DM deberán efectuar automonitoreo glucémico los días previos para la adecuación de las dosis de fármacos y la eventual suspensión de los mismos, especialmente quienes estén con sulfonilureas o insulina'. Es fundamental que el paciente reconozca síntomas de hipoglucemia y conozca el tratamiento adecuado antes de la cirugía.

Se sugiere suspender las sulfonilureas y disminuir la dosis de insulina empíricamente desde el inicio de la dieta pre-CB. Para los ajustes de dosis es imprescindible que el paciente realice al menos dos monitoreos diarios. Se sugiere mantener glucemias entre 110 y 180 mg/dl2 . La metformina debería suspenderse 48 h antes de la cirugía y evaluar el riesgo de acidosis láctica. Tanto los iDPP-4 como los agonistas del receptor GLP-1 y las glitazonas pueden mantenerse hasta el día 
previo a la $\mathrm{CB}^{1}$. Si bien no existe contraindicación para el uso de iSGLT-2 en esta prequirúrgica, debe controlarse estrictamente el estado hemodinámico y considerar riesgo de hipotensión ortostática.

\section{Día de la cirugía}

Todos los pacientes deben realizar automonitoreo glucémico para ingresar a cirugía con glucemias entre 110 y 180 mg/dl. En el caso de insulina como tratamiento previo, algunos autores sugieren un manejo similar al indicado para cualquier cirugía (uso del $50 \%$ de dosis usual) 1 . En opinión de este grupo de expertos, en pacientes con DM asociada a obesidad debe suspenderse la insulina basal desde el día de la cirugía; solo debe indicarse el $50 \%$ de dosis basal en pacientes con DM1.

El monitoreo glucémico debe realizarse cada $6 \mathrm{~h}$ mientras el paciente permanezca en ayunas y preprandiales desde el momento en que reinicia alimentación oral. De ser necesario se usará insulina rápida o ultrarrápida subcutánea para mantener valores en rango".

\section{Poscirugía}

Luego de la CB se modifica la biodisponibilidad de los fármacos por la alteración de la superficie de absorción, cambio de la composición corporal y del clearence al alterarse bruscamente el circuito entero-hepático y metabolismo hepático?.

Los fármacos de administración oral deben ser desintegrados y disueltos en el estómago para su correcto pasaje al duodeno, proceso que depende de la motilidad gástrica y de la cantidad de fluidos que contenga el estómago (ambos pueden estar disminuidos pos-CB) y del pH gástrico (significativamente aumentado pos-CB) ${ }^{3}$.

Dado que no existe una guía actual del manejo de los antidiabéticos orales en estos pacientes, se recomienda el control estricto y seguimiento personalizado de cada paciente.

La metformina, recomendado como fármaco de primera elección, fue estudiado desde el punto de vista farmacocinético en una cohorte de 16 pacientes con CB en Y de Roux vs controles, y se evidenció aumento de la biodisponibilidad del 50\% de la droga y reducción significativa del Tmax en pacientes operados vs controles, por lo que se recomienda iniciar con dosis bajas (500 mg/día) y titular según respuesta del paciente ${ }^{3}$. En Argentina se comercializa también la formulación en solución, con menos dificultad de absorción en algunos pacientes, aunque no hay evidencia al respecto.
De no ser tolerada la metformina, o en caso de contraindicación por caída del FG, deben priorizarse fármacos que faciliten el descenso de peso o resulten inocuos en este sentido 4 .

No se recomienda el uso de glitazonas por el efecto negativo sobre el peso, ni de sulfodrogas por el aumento del riesgo de hipoglucemia en estos pacientes $1,2,4$.

Si bien no hay trabajos prospectivos con iDPP-4, se utilizan frecuentemente en pacientes pos-CB con buenos resultados.

El fármaco más estudiado en estos casos es liraglutide, ya que se lo utiliza para evitar la reganancia de peso por su acción a nivel del sistema nervioso central sobre los centros del hambre y saciedad $^{5}$. Una de sus ventajas es la administración subcutánea, salteando las posibles dificultades en la absorción observada en fármacos orales ${ }^{3}$. Puede utilizarse en pacientes con FG hasta $15 \mathrm{ml} /$ minuto y tiene alta eficacia en la reducción de $\mathrm{HbA} 1 \mathrm{c}$, siendo de elección antes que la insulina en pacientes en los que es prioridad favorecer el descenso de peso. El reporte de reacciones adversas es similar al observado en pacientes no operados, con náuseas del 30 al 38\% de casos en las primeras semanas con remisión posterior, con baja tasa de abandono del tratamiento por esta causa ${ }^{5}$.

\section{DM pos-CB}

El diagnóstico se realiza con dos glucemias $\geq 126 \mathrm{mg} / \mathrm{dl}$ en ayunas o con una glucemia $\geq 200 \mathrm{mg} / \mathrm{dl}$ con síntomas cardinales. No puede utilizarse la prueba de tolerancia oral a la glucosa dada la alteración en la absorción en estas cirugías. Deben diferenciarse tres situaciones ${ }^{6}$ :

- No remisión en paciente con adecuado descenso de peso posoperatorio o reaparición posterior a breve período de remisión; repetir dosaje de péptido $\mathrm{C}$ y anticuerpos para descartar DM1 o latent autoimmune diabetes in adults (LADA).

- No remisión en paciente con descenso inferior al esperado.

- Reaparición de DM ante reganancia de peso.

\section{BIBLIOGRAFÍA}

1. Thorell A, Hagström-Toft E. Treatment of diabetes prior to and after bariatric surgery. Journal of Diabetes Science andTechnology 2012; 6 (5):1226-1232.

2. Mechanick JI, Youdim A, Jones DB. Clinical Practice Guidelines for the perioperative nutritional, metabolic, and nonsurgical support of the bariatric surgery patient 2013. Update: cosponsored by American Association of Clinical Endocrinologists. The Obesity Society and American Society for Metabolic and Bariatric Surgery. Endocrine Practice 2013; 19:1-36. 
3. Azran C, Wolk O, Zur M, et al. Oral drug therapy following bariatric surgery: an overview of fundamentals, literature and clinical recommendations. Obesity Review 2016; 17(11):10501066. DOI: 10.1111/obr. 12434.

4. Shah A, Laferrère B. Diabetes after bariatric surgery. Can J Diabetes $2017 ; 41(4)$ : 401-406.
5. Rye P, Modi R, Cawsey S, et al. Efficacy of high-dose liraglutide as an adjunct for weight loss in patients with prior bariatric surgery. Obesity Review 2018; 28(11):3553-3558.

6. Khanna V, Kashyap SR. Clinical management of type 2 diabetes mellitus after bariatric surgery. Curr Atheroscler Rep 2015; 17(10):59.

\section{Cambios generados sobre el estado metabólico en pacientes con DM sometidos a CB}

\section{Mejoras tempranas}

El evento temprano más importante es probablemente el gran cambio que ocurre en la resistencia a la insulina hepática a los pocos días de la cirugía, alcanzando aproximadamente el $50 \%$ de los valores preoperatorios después de solo una semana. Este cambio se debería a la restricción calórica posoperatoria (Figura 1), con la consiguiente pérdida de grasa hepática, como se demostró mediante el uso de imágenes de resonancia magnética para grasa visceral'

Los cambios tempranos en la sensibilidad a la insulina hepática conducen a un rápido descenso de las concentraciones basales de glucosa, lo cual puede contribuir a la eliminación del efecto glucotóxico sobre las células beta pancreáticas, como lo demuestra el rápido aumento de la primera fase de secreción de insulina en pacientes con DM21.

Así como la disminución de la grasa hepática ocurre a los siete días posquirúrgicos, los estudios demostraron que la reducción de la grasa pancreática sucede luego de ocho semanas'.

\section{Digestión y absorción de nutrientes}

Tan pronto como el paciente recién operado comienza a ingerir nutrientes, se establece otro mecanismo que colabora en las mejoras metabólicas: la entrada de nutrientes en el intestino delgado más distal a través de la extremidad de Roux (la extremidad alimentaria) se acelera enormemente ${ }^{2}$.

Si bien se ha demostrado un mayor aumento posprandial temprano en la concentración de glucosa en plasma, el mismo es seguido de un rápido descenso a niveles mucho más bajos después de 1 a 2 h en comparación con los valores preoperatorios. Si bien existe una absorción rápida de la glucosa, también es veloz la secreción de insulina y no se traduce en un aumento de la glucemia ${ }^{2}$.

En la Figura 2 se enumeran los principales mecanismos involucrados en la mejoría de la homeostasis glucémica.

\section{Teoría del intestino distal. Estimulación de la secreción enterohormonal}

Las modificaciones del tránsito intestinal posCB generan una llegada precoz del alimento al intestino distal (yeyuno distal-íleon), con estimulación de las células $L$ del epitelio intestinal y producción de GLP-1 y PYY (anorexígeno). Este perfil de secreción de enterohormonas se establece precozmente en el posoperatorio. La glucosa, que es el estímulo más importante para la secreción de GLP-1 después de la cirugía, se transporta intracelularmente por el transportador sodio-glucosa cotransportador-1 (SGLT-1) y desencadena su secreción. También se ha sugerido que los ácidos biliares desempeñan un papel y pueden contribuir en el estímulo para la secreción de GLP-1, como se mencionará más adelante ${ }^{3}$.

\section{Teoría del intestino proximal}

Hickey (1998) y Pories (2001) fueron los primeros en señalar la posible función de la exclusión del intestino proximal en la remisión de la DM2, y sugirieron el exceso de producción de un "péptido diabetogénico" en duodeno y yeyuno proximal. Más tarde, el trabajo experimental realizado por Rubino et al. en ratas Goto Kakizaky (ratas diabéticas no obesas) demostró con éxito esta hipótesis al inducir quirúrgicamente la remisión de la DM2 mediante la exclusión del intestino proximal y luego revertir los cambios al restablecer el paso normal de los alimentos en este segmento. Estas "señales diabetogénicas" podrían ser factores anti incretinas no conocidos. Se supone que el glucagón de origen intestinal podría ser uno de estos factores involucrados ${ }^{2,3}$.

Si la restricción gástrica es amplia, también disminuye la grelina, enterohormona expresada principalmente en las células del fondo gástrico. Es un potente orexígeno a nivel central, además de ser capaz de disminuir la secreción de insulina y bloquear las vías de señalización de la misma a nivel hepático. Los niveles de grelina plasmática en personas sometidas a bypass gástrico no oscilan en relación con los tiempos de comida, por el 
contrario, se mantienen en niveles marcadamente menores $(<65 \%$ en la secreción y concentración plasmática) a pesar de la pérdida de peso ${ }^{2,3}$.

\section{Cambios en la microbiota intestinal}

Luego de la cirugía disminuye la alta proporción de firmicutes (perfil bacteriano obeso) y aumenta la proporción de bacteroidetes (perfil bacteriano de pacientes delgados). Los bacteroidetes desempeñan un papel clave en la desconjugación de ácidos biliares y puede afectar la composición de los mismos. Los ácidos biliares podrían ser reguladores importantes del balance energético y el metabolismo, principalmente a través del receptor nuclear farnesoide $X$ ( $F X R$, por sus siglas en inglés) y de la proteína $\mathrm{G}$ acoplada receptor TGR5. Luego de la ingesta, los ácidos biliares se liberan al duodeno para tomar contacto con los alimentos y se reabsorben activamente en el íleon terminal, volviendo así a la circulación portal. Una pequeña parte, el 5\% de las sales biliares (ácidos biliares conjugados con glicerina y taurina), escapa a la circulación enterohepática y es desconjugada por la microbiota intestinal formando los ácidos bilia- res secundarios. El flujo de ácidos biliares activa el FXR intestinal e induce la síntesis y la secreción en la circulación de una enteroquina derivada del íleo FGF-19 (FGF-15 en ratones). FGF-19 inhibe la expresión de la enzima colesterol 7 a hidroxilasa-1, el paso limitante de la síntesis de ácidos biliares. En ratones, el FGF-15 puede disminuir la producción hepática de glucosa ${ }^{4}$.

\section{Mayor disponibilidad de \\ ácidos biliares en el íleon}

Algunos procedimientos bariátricos contribuyen a una mayor disponibilidad de ácidos biliares (primarios y secundarios) en el íleon, con propiedades antimicrobianas y la consecuente reducción del tamaño de las subpoblaciones bacterianas. Los ácidos biliares secundarios disminuyen la captación hepática de ácidos grasos libres y afectan así el metabolismo de los triglicéridos y la localización en sitios fuera del tejido adiposo. Como se observa en las Figuras 3 y 4, sus blancos de acción son el adipocito, hepatocito, páncreas y músculo, por lo cual, de forma directa o indirecta, mediado por FGF-19, FXR oTGR-5, mejoran el perfil metabólico 4 .

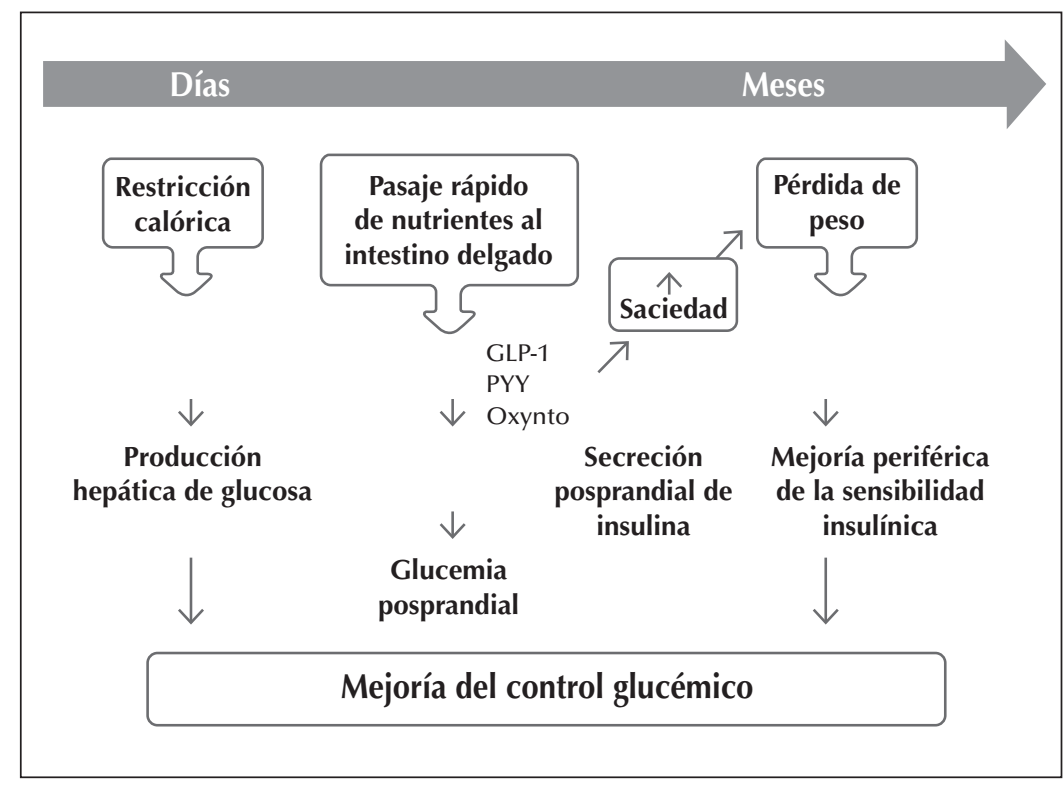

Adaptado de: Dirksen $C$, et al. ${ }^{1}$.

Figura 1: Cambios metabólicos secundarios a CB que mejoran el control glucémico. 


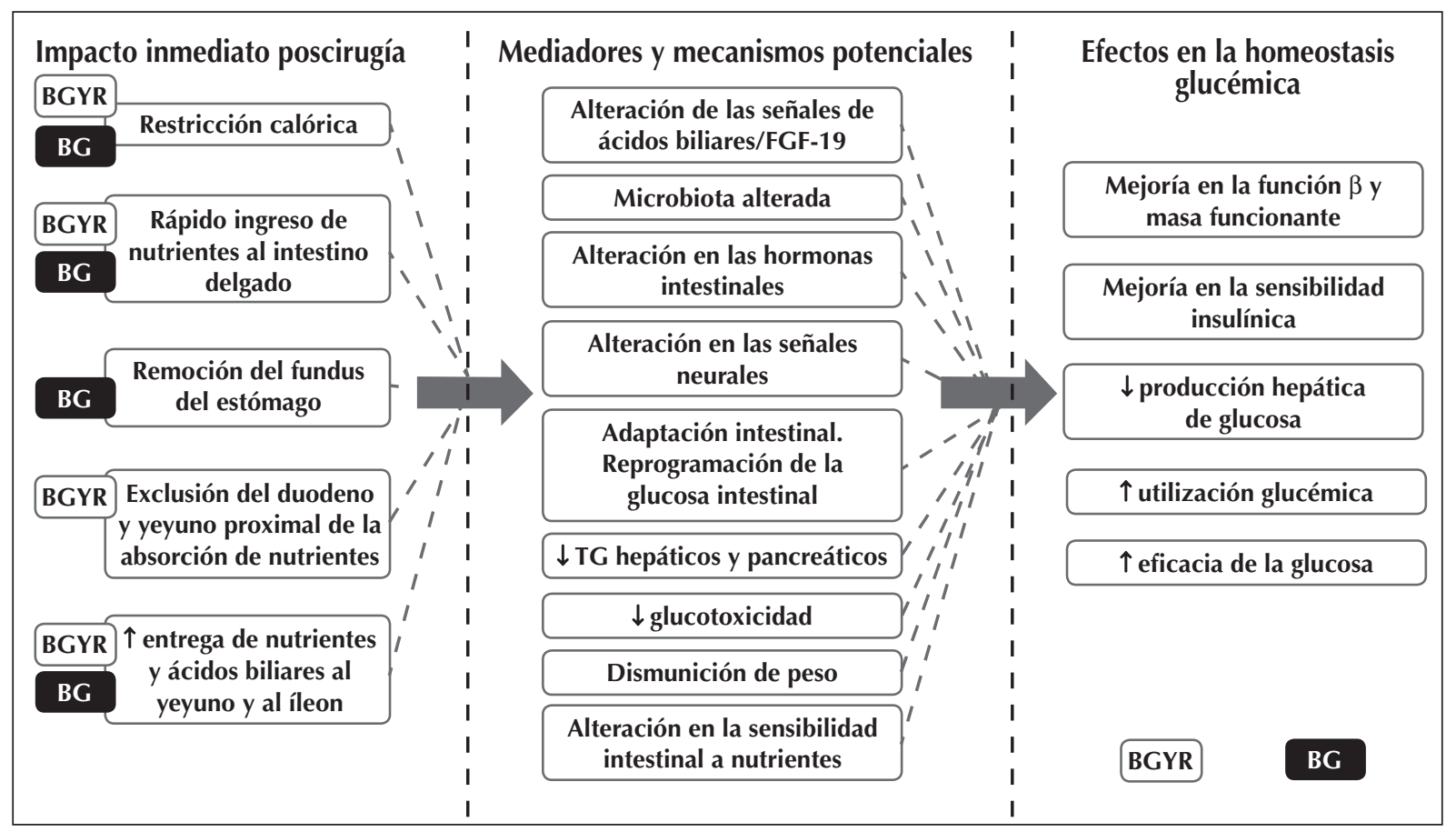

Adaptado de: Batterham RL, et al ${ }^{2}$.

BG: banda gástrica; BGYR: bypass gástrico en Y de Roux; FGF-19: factor de crecimiento de fibroblastos de 19; TG: triglicéridos.

Figura 2: Mediadores y mecanismos potenciales que provocan efectos beneficiosos sobre la homeostasis glucémica.

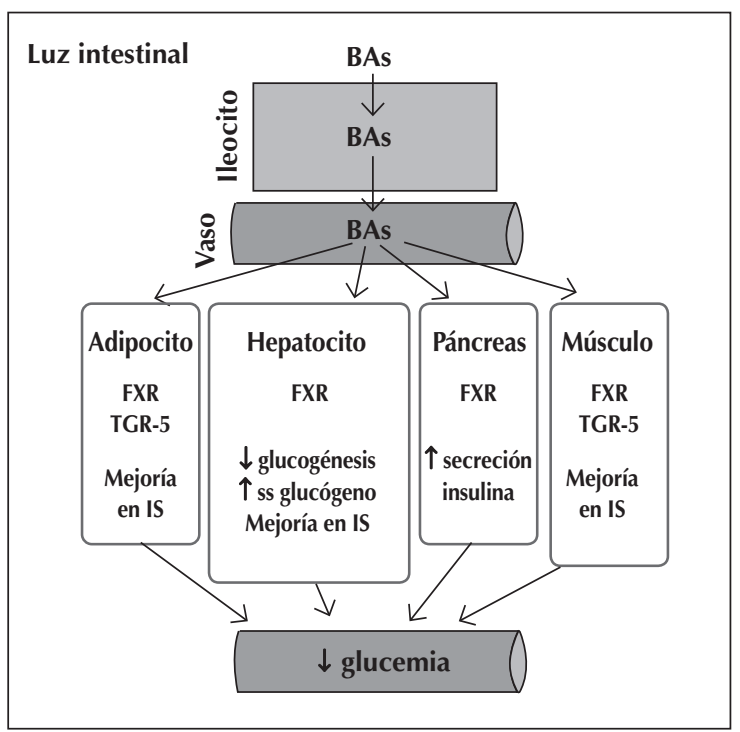

Adaptado de: Kaska L, et al. ${ }^{4}$.

BAs: ácidos biliares; FXR: receptor nuclear farnesoide $X$; SS: síntesis; IS: insulinosensibilidad.

Figura 3: Los ácidos biliares circulantes activan a los receptores FXR yTGR-5, y esto regula la expresión de genes involucrados en mejoría de la glucemia.

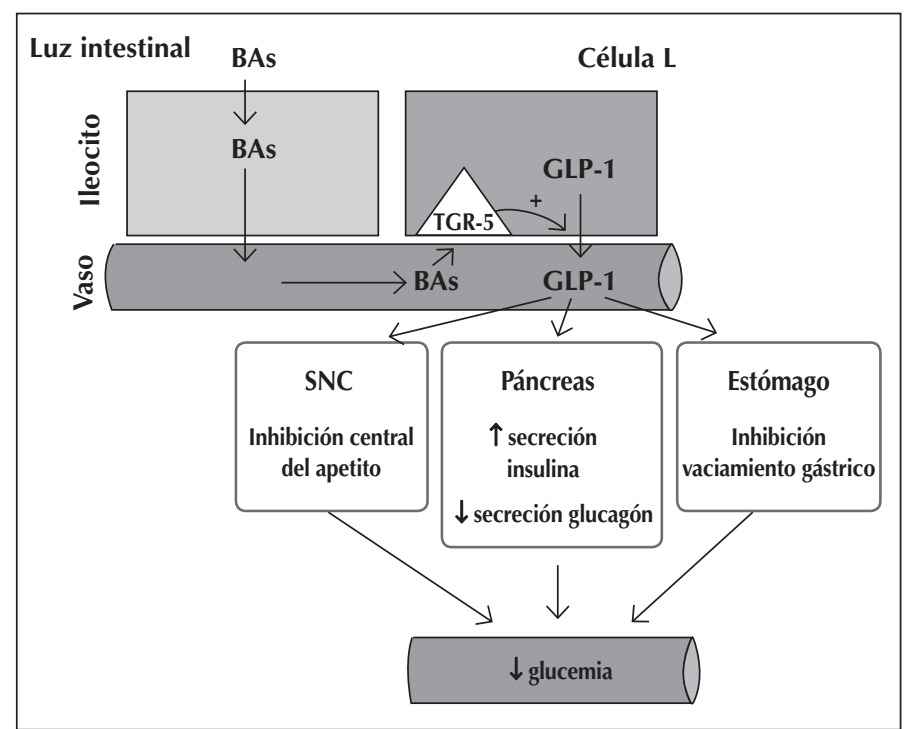

Adaptada de: Kaska L, et al. ${ }^{4}$

SNC: sistema nervioso central.

Figura 4: Los ácidos biliares víaTGR5 estimulan la secreción de PYY y GLP-1 por las células $L$. 


\section{BIBLIOGRAFÍA}

1. Dirksen C, Jørgensen NB, Bojsen-Møller KN, et al. Mechanisms of improved glycaemic control after Roux-en-Y gastric bypass. Diabetologia 2012; 55(7):1890-901. DOI: 10.1007/s00125-0122556-7.

2. Batterham RL, Cummings DE. Mechanisms of diabetes improvement following bariatric/metabolic surgery. Diabetes Care 2016; 39:893-901. DOI: 10.2337/dc16-0145.
3. Seeley RJ, Chambers AP, Sandoval DA. The role of gut adaptation in the potent effects of multiple bariatric surgeries on obesity and diabetes. Cell Metab 2015; 21(3): 369-378. DOI: 10.1016/j.cmet.2015.01.001.

4. Kaska, L, Sledzinski T, Chomiczewska A, et al. Improved glucose metabolism following bariatric surgery is associated with increased circulating bile acid concentrations and remodeling of the gut microbiome. World J Gastroenterol 2016 October 21; 22(39):86988719. DOI: $10.3748 /$ wjg.v22.i39.8698

\section{Cambios en la microbiota intestinal después de la CB}

\section{¿Cambia la microflora intestinal y la abundancia de riqueza genética después de la CB?}

Los resultados son altamente contradictorios. En un estudio realizado en China se encontró que la gastrectomía en manga se asoció a una modificación de la flora intestinal. En estudios de metagenómica ampliada, comparando sujetos obesos y delgados, se encontró baja diversidad genética en la microflora de los sujetos obesos y relación inversa entre el cociente bacteroidetes/firmicutes y el grado de obesidad. Se conoce que los sujetos obesos tienen un mayor potencial de producir aminoácidos aromáticos (AAA) y aminoácidos ramificados (BCAA, sus siglas en inglés). Los niveles de glutamato, altamente elevados, presentan una correlación positiva con el IMC, la circunferencia de cintura, el HOMA IR, la proteína $C$ reactiva y el triacilglicerol; el nivel elevado de glutamato estaría determinado por la ausencia intestinal de ciertas especies como bacteroides thetaiotamicron, que junto con la Akkermansia muciniphyla tiene efectos importantes en el mantenimiento de la integridad de la mucosa intestinal, e impiden el transporte de lipopolisacáridos y la activación de citoquinas inflamatorias como TNF $\alpha$ e interleukina ${ }^{6}$. La especie B. thetaiotamicron posee genes que codifican la glutamato decarboxilasa, convirtiendo este compuesto en GABA. Por lo tanto, la depleción de la misma contribuye a que este paso metabólico no tenga lugar y se incrementan los niveles séricos de glutamato. En el estudio citado, la gastrectomía en manga se asoció a un incremento de la presencia de flora de $B$. thetaiotamicron y a una disminución de los niveles de glutamato pos-CB? .

Otros estudios demostraron incremento de la variedad de riqueza genética pos-BGYR. Analizando la microflora intestinal después del BGYR, se encontró un incremento significativo de la diversidad genética de la microflora intestinal, en particular un aumento del $37 \%$ de las especies del género proteobacteria. Los autores utilizaron 16S ARN primers con PCR de secuenciación. Genes de las especies de firmicutes como Lactobacillos, Dorea y Blautia disminuyeron después de la cirugía, mientras que Phyllum Bacteroidetes, bifidobacterias, actinobacterias aumentaron. En particular el género E. Coli aumentó considerablemente ${ }^{2}$.

Por el contrario en un estudio de cohorte de 61 pacientes obesos con BGYR o banda gástrica, analizando la microflora por shotgun metagenomics y espectrometría de masas por cromatografía líquida, si bien se encontraron significativas mejorías metabólicas ya sea en los parámetros glucémicos como lipídicos, no se observó ninguna modificación significativa de la microflora al año del procedimiento quirúrgico. La utilización de banda gástrica incrementó parcialmente el bajo conteo genético al año. Tanto en el grupo asignado al tratamiento con banda gástrica como a BGYR se observó basalmente una fuerte correlación inversamente negativa entre la riqueza genética de la flora intestinal y el IMC, masa grasa, presencia de hipertensión o alteración de la curva de tolerancia a la glucosa. La conclusión de este estudio fue que, pese a encontrar una significativa mejoría metabólica en los pacientes sometidos a $\mathrm{CB}$, la microflora persistía con baja riqueza genética microbiana al año del procedimiento, cuestionando la importancia de la modificación de la microflora intestinal en los beneficios atribuibles a la $\mathrm{CB}^{3}$.

\section{BIBLIOGRAFÍA}

1. Liu R, Hong J, Xu X, et al. Gut microbiome and serum metabolome alterations in obesity and after weight loss intervention. Nat Med 2017; 23(7):859-868 DOI:10.1038/nm.4358

2. Chun Long L, Tap J, Aron-Wisnewsky J, et al. Gut microbiota after gastric bypass in human obesity increased richness and associations of bacterial genera with adipose tissue genes. Am J Clin Nutr 2013; 98(1):16-24. DOI: 10.3945/ajcn.113.058743.

3. Aron-Wisnewsky J, Prifti E, Belda E, et al. Major microbiota dysbiosis in severe obesity: fate after bariatric surgery. Gut 2018; 0,1 13. DOI:10.1136/gutjnl-2018-316103. 


\section{CB en pacientes con ERC y en tratamiento sustitutivo candidatos a trasplante renal}

En Argentina solo el 19\% de los más de 30 mil pacientes en diálisis está inscripto en lista de espera para un trasplante renal, mientras que cada año se trasplanta solo el $20 \%$. La mayor parte recibe el órgano de un donante cadavérico con un tiempo promedio de espera de tres a siete años y la mortalidad en lista de espera es del $27 \%$. Existen situaciones que dificultan aún más el acceso de los pacientes con ERC a un trasplante, como la exclusión de aquellos con diferentes grados de obesidad en la mayor parte de los centros, por lo que consideramos un tema que debería abordarse y protocolizar a la brevedad².

Muchos estudios demostraron que la CB mejora la DM y sus complicaciones microvasculares, incluida la nefropatía ${ }^{3}$. En un estudio suizo de casi 4.000 pacientes con obesidad con un seguimiento promedio de 18 años, se observó que la CB se asoció a menor incidencia de ERC a largo plazo, con disminución del $70 \%$ de todos los casos de ERC y del $65 \%$ de los casos de ERC E4, siendo el beneficio mayor en aquellos pacientes con mayor nivel de insulina sérica y albuminuria basal ${ }^{3}$. Otros estudios reportaron una mejoría significativa en los parámetros renales pos bypass gástrico, con resolución, mejoría o estabilización de la función renal ${ }^{4,5}$. Se ha publicado un caso de recuperación de la función renal pos-CB en un paciente en diálisis ${ }^{6}$. Además, en un estudio de pacientes con obesidad mórbida y DM2, el cambio en el IMC 12 meses después de la CB fue el único predictor independiente de normalización del índice albuminuria-creatininuria?. La obesidad es un factor de riesgo reversible de ERC y enfermedad cardiovascular, y su tratamiento influye favorablemente en todos los demás factores asociados. Cuando se revierte la obesidad, muchos de los factores de riesgo de ERC disminuyen drásticamente como la hipertensión arterial (HTA), DM, dislipemia, inflamación, activación del sistema renina-angiotensina-aldosterona (SRAA) y el síndrome metabólico ${ }^{8}$. La CB debería considerarse especialmente para el tratamiento de pacientes obesos con daño renal establecido y la ERC podría añadirse a la lista de comorbilidades asociadas.

En pacientes con ERC terminal, el trasplante renal se considera el tratamiento de elección. Estos procedimientos quirúrgicos son más dificultosos en personas con obesidad: tiempos quirúrgicos más prolongados, mayor tasa de complicaciones posoperatorias, infecciones del sitio quirúrgico, lin- focele e internaciones más prolongadas ${ }^{9,10}$. Por otro lado, la mayor mortalidad cardiovascular asociada a la obesidad es uno de los principales determinantes por la cual los centros de trasplante limitan el ingreso a la lista de espera. Está demostrado que la posibilidad de acceder a un trasplante renal disminuye cuanto mayor es el IMC 9.10 .

No existe evidencia clara respecto de un punto de corte de IMC para excluir a pacientes como candidatos a trasplante, de manera que cada centro se rige por sus propias valoraciones y experiencias. Las guías European Renal Best Practice Trasplantation sugieren que los pacientes con IMC $\geq 30 \mathrm{~kg} / \mathrm{m}^{2}$ deben descender de peso antes del trasplante. Las guías British Renal Association recomiendan que los pacientes con IMC $\geq 40 \mathrm{~kg} / \mathrm{m}^{2}$ presentarían un menor beneficio con el trasplante que aquellos con menor IMC. Por su parte, las guías de la European Association of Urology plantean que el trasplante otorga una mayor supervivencia y calidad de vida en pacientes obesos en diálisis y que no existe suficiente evidencia para recomendar la exclusión de pacientes basada en el IMC ${ }^{2}$. Debido a la epidemia de obesidad los centros se flexibilizaron, pero reconocen utilizar el IMC como criterio limitante en IMC entre 35 a $45 \mathrm{Kg} / \mathrm{m}^{2}{ }^{11}$.

La obesidad se asocia a un aumento significativo de la morbilidad y mortalidad en la población general, sin embargo, un IMC elevado se asoció a mayor supervivencia en hemodiálisis: "epidemiología inversa" 12 . El riesgo de mortalidad ha sido más bajo en pacientes en hemodiálisis con IMC entre 25 y $39,9 \mathrm{~kg} / \mathrm{m}^{2}{ }^{13}$. Otro estudio evidenció un aumento de la mortalidad en hemodiálisis crónica en valores extremos de IMC: curva en forma de "U"8,14. Posteriormente, se observó que la asociación de mayor IMC con mayor sobrevida en los pacientes en hemodiálisis se limita a aquellos con excreción normal o elevada de creatinina urinaria (marcador de masa muscular). Al contrario, pacientes en hemodiálisis con mayor IMC, pero baja masa muscular medida por creatinina urinaria y alto contenido de tejido adiposo, presentan mayor mortalidad vs pacientes con IMC normal. Según estudios, en sujetos con ERC el espesor del pliegue cutáneo y el índice cintura/cadera es superior al IMC para la correcta clasificación de la obesidad ${ }^{14}$.

La ganancia de peso postrasplante es un evento común y se duplica en el primer año postrasplante $(5,6$ a $11,4 \%)$, con peor pronóstico a largo plazo para el paciente y el injerto. Los receptores obesos de trasplante renal tienen un $38 \%$ más de probabi- 
lidades de perder el injerto a los cinco años que los no obesos ${ }^{10}$. Se observa también mayor tasa de retraso en la función del injerto y de rechazos agudos. La obesidad en el postrasplante se asocia también a menor sobrevida debido a la presencia de comorbilidades asociadas HTA, DM, enfermedad cardiovascular y dislipemia. Si bien los pacientes obesos presentan en el postrasplante mayor morbimortalidad respecto de aquellos trasplantados con peso normal, los obesos que se trasplantan presentan menor mortalidad vs persistir en lista de espera, claramente en valores de $\mathrm{IMC} \geq 30 \mathrm{~kg} / \mathrm{m}^{2}$ y con menos estudios realizados en $I M C \geq 40 \mathrm{~kg} / \mathrm{m}^{22}$.

La pérdida de peso previa al trasplante es dificultosa en pacientes con ERC, aún en quienes se incluyen en programas para descenso de peso. Se estima en menos del $10 \%$ al momento de la evaluación pretrasplante y menos del $5 \%$ logra el objetivo de IMC $\leq 30 \mathrm{~kg} / \mathrm{m}^{2}$ solicitado por muchos centros. Los estudios demuestran que la CB permite alcanzar el peso requerido para acceder más rápidamente a la lista de espera ${ }^{10}$.

La CB se indica con IMC $\geq 40 \mathrm{~kg} / \mathrm{m}^{2} \mathrm{o} \geq 35 \mathrm{~kg} / \mathrm{m}^{2}$, con enfermedad asociada a obesidad. La mayoría de los pacientes con ERC e IMC $\geq 35 \mathrm{~kg} / \mathrm{m}^{2}$ presenta HTA y DM, y pueden ser candidatos a CB.

Los estudios demuestran que existe mayor riesgo de complicaciones en estadios avanzados de ERC, como infección del sitio quirúrgico, complicaciones pulmonares, reintubación, ventilación posoperatoria más prolongada y shock séptico ${ }^{15}$. Posterior a la CB se produce disminución de la absorción de vitamina $D$ y de los niveles séricos de calcio, lo cual puede incrementar los niveles de PTH y disminución de la masa ósea, hecho que debe particularmente evaluarse previo a la cirugía en pacientes con ERC, los cuales ya presentan enfermedad ósea mineral. Suplementos de calcio y vitamina $D$, adecuada ingesta de proteínas y los controles con densitometrías óseas en el posoperatorio son obligatorios en estos pacientes ${ }^{16}$.

Por ende, hay que estimular al paciente obeso con ERC a perder peso lo más temprano posible en cada estadio de la ERC o previo al trasplante renal. Esto reduce las complicaciones posoperatorias, mejora el funcionamiento inicial del injerto, permite el tratamiento de la DM y la HTA al reducir el requerimiento de medicaciones para estas patologías, mejorar la sobrevida del injerto y disminuir la mortalidad cardiovascular a largo plazo ${ }^{10}$.

\section{BIBLIOGRAFÍA}

1. SINTRA. Disponible en: www.sintra.incucai.gov.ar.

2. Hossain M, Woywodt $A$, Augustine T, et al. Obesity and listing for renal transplantation: weighing the evidence for a growing problem. Clin Kidney J 2017;10(5): 703-708.

3. Segev DL, Simpkins CE, Thompson RE, et al. Obesity impacts access to kidney transplantation. J Am Soc Nephrol 2008; 19(2): 349-355.

4. Alexander JW, Goodman HR, Hawver LR, et al. Improvement and stabilization of chronic kidney disease after gastric bypass. Surg Obes Relat Dis 2009; 5(2):237-241.

5. Hou CC, Shyu RS, LeeWJ, et al. Improved renal function 12 months after bariatric surgery. Surg Obes Relat Dis 2013; 9(2):202-6.

6. Tafti BA, Haghdoost M, Álvarez L, et al Recovery of renal function in a dialysis-dependent patient following gastric bypass surgery. Obes Surg 2009; 19(9):1335-39.

7. Amor A, Jiménez A, Moizé V, et al. Weight loss independently predicts urinary albumin excretion normalization in morbidly obese type 2 diabetic patients undergoing bariatric surgery. Surg Endosc 2013; 27:2046-2051.

8. Zalesin KC, McCullough PA. Bariatric surgery for morbid obesity: risks and benefits in chronic kidney disease patients. Adv Chronic Kidney Dis 2006; 13(4):403-17.

9. Segev DL, Simpkins CE, Thompson RE, et al. Obesity impacts access to kidney transplantation. J Am Soc Nephrol 2008; 19(2):349-355.

10. Chan G, Garneau P, Hajjar R. The impact and treatment of obesity in. Canadian Journal of Kidney Health and Disease 2015; 26:2-26.

11. Krista KL, De los Santos R, Axelrod D, et al. Obesity and kidney transplant candidates: how big is too big for transplantation? Am J Nephrol 2012; 36 (6):575-586.

12. Leavey $S F$, Strawderman $R L$, Jones $C A$, et al. Simple nutritional indicators as independent predictors of mortality in hemodialysis patients. Am J Kidney Dis 1998; 31(6): 997-1006.

13. Leavey SF, McMullough $K$, Hecking $E$, et al. Body mass index and mortality in healthier as compared with sicker haemodialysis patients: Results from the Dialysis Outcomes and Practice Patterns Study. Nephrol DialTransplant 2001; 16(12):2386-94.

14. Shulman A, Peltonen $M$, Sjöström $C D$, et al. Incidence of endstage renal disease following. Int J Obes 2018; 42(25):964-973.

15. Turgeon NA, Pérez $S$, Mondestin M. The impact of renal function on outcomes of bariatric. J Am Soc Nephrol 2012; 23(5):885-894.

16. Williams SE. Metabolic bone disease in the bariatric surgery patient. J Obes 2011; 1-9.

\section{Complicaciones renales y óseas a largo plazo y su control posquirúrgico}

La CB demostró ser un método efectivo para asegurar la reducción de peso a largo plazo. Si bien se han confirmado importantes beneficios sobre mortalidad, enfermedad y factores de riesgo cardiovascular, pocas publicaciones abordaron la incidencia de complicaciones a largo plazo en pacientes con obesidad y DM2 que se sometieron a CB'1.

Liakopoulos $\mathrm{V}$ et al. ${ }^{1}$ publicaron los datos del Registro Nacional Sueco de Diabetes (NDR, por 
sus siglas en inglés) y el Registro de Cirugía de Obesidad Escandinava (SOReg, por sus siglas en inglés). Evaluaron 5.321 pacientes que realizaron CB y los compararon con 5.321 controles con obesidad con un seguimiento a nueve años. Los individuos que realizaron $\mathrm{CB}$ presentaron mayor prevalencia de complicaciones. Las complicaciones posoperatorias poco después de la $\mathrm{CB}$ más frecuentes fueron: fístulas (HR: 5,54 IC95\%: 2,46-12,45), complicaciones de la herida (HR: 3,45 IC95\%: 2,70-4,42) y úlcera/reflujo (HR: 5,42 IC95\%: 3,91-7,51), mientras que otros generalmente aumentaron después de uno o dos años de la cirugía como hernias (HR: 2,75 IC95\%: 2,143,54), obstrucción intestinal (HR: 9,47 IC95\%: 6,31-14,20), y enfermedad biliar y pancreatitis (HR: 2,49 IC95\%: 2,02-3,08). La falta de adherencia a la toma de los suplementos vitamínicos y minerales, y el seguimiento errático de los pacientes posibilitan que la anemia (HR: 1,9 IC95\%: 1,33-2,79) y la malnutrición (HR: 2,81 IC95\%: 1,98-3,97) sean complicaciones a largo plazo muy frecuentes. Otras complicaciones a largo plazo son los trastornos psiquiátricos (HR: 1,33 IC95\%: 1,13-1,58) y el abuso de alcohol (HR: 2,90 IC95\%: 2,16-3,88). La hipoglucemia pos-CB en Y de Roux (BGYR) es una complicación que se presenta luego del año de la cirugía (por definición) cuya prevalencia puede alcanzar el 34\% siendo solo un $11,6 \%$ sintomática ${ }^{2}$.

Diferentes publicaciones sugirieron beneficios de la CB sobre la ERC (HR: 0,58 IC95\%: 0,45$0,75)^{3-5}$, pero pocos estudios hacen referencia a las complicaciones, como el desarrollo de hiperoxaluria y litiasis renal que puede afectar al 16\% de los casos ${ }^{6}$. En este apartado se mencionan estas complicaciones renales y el déficit de vitamina $D$ debido al impacto que presenta la misma sobre el riñón y el metabolismo fosfocálcico.

\section{Hiperoxaluria y litiasis renal}

Diferentes autores hallaron en individuos sometidos a BGYR un incremento de hasta un 25\% de hiperoxaluria, un $60 \%$ de aumento del oxalato en plasma, con una disminución del $40 \%$ de citraturia acompañada de un 30-60\% de reducción del volumen urinario, lo que conlleva a un incremento significativo de la supersaturación de oxalato de calcio que favorece la formación de litiasis ${ }^{6,7}$.

La prevalencia depende del tipo de CB y de los antecedentes de litiasis. En los procesos malabsortivos (BGYR) con antecedentes de litiasis renal alcanza el $16,7 \%$, mientras que en aquellos sin antecedentes el 8,4\%. Otros autores descubrieron una incidencia de 16,62 litos/1.000 personas/año, siendo en obesos de 11,3 litos/1.000/año. En los procesos restrictivos la prevalencia se asemeja a los controles sanos entre 1,3-4,7\% ${ }^{8}$. Cabe destacar que la aparición de hiperoxaluria y su consecuencia, la formación de litos, se incrementan con el tiempo ${ }^{8,9}$.

El mecanismo fisiopatológico comprende: hiperoxaluria, hipocitraturia, aciduria, disminución del volumen urinario, supersaturación urinaria de oxalato de calcio y riesgo de formación de litiasis.

El oxalato es un producto del metabolismo de los aminoácidos y es absorbido en el estómago, intestino delgado y colon. Todo el oxalato absorbido es excretado sin cambios por orina. El calcio y el oxalato de la dieta precipitan en la luz intestinal y son excretados por materia fecal. En las cirugías malabsortivas, como BGYR, los ácidos grasos no absorbidos se unen preferentemente al calcio (saponificación) y dejan disponible al oxalato que se concentra en el colon donde existe un aumento de la permeabilidad por alteración de las uniones tight que permite que el mismo difunda pasivamente a sangre. En forma experimental se observó que este tipo de cirugía aumentaría los transportadores de aniones (SCL26 A3) con una disminución de los SCL26 A6 en la membrana apical del enterocito: los primeros favorecen el ingreso de oxalato, los segundos provocan la excreción de oxalato; además existe un aumento del número de SCL26 A1 en la membrana basolateral incrementando su pasaje a plasma, el mismo luego es filtrado y excretado por riñón ${ }^{6}$.

Asimismo, existen bacterias que degradan el oxalato en la luz intestinal, la principal es Oxalobacter formigenes. Las CB tipo BGYR alteran la flora intestinal con una reducción de dichas bacterias, de esta forma disminuye la degradación de oxalato y aumenta su absorción. Además, el déficit de vitamina B6, característico de las cirugías malabsortivas, a través de su metabolismo activo -el fosfato de piridoxal- actúa como cofactor de la transaminación de glioxilato a glicina, el déficit de vitamina B6 produce un desvío hacia la producción de oxalato hepático. En la Figura 1 se explica el mecanismo de la hiperoxaluria 6 .

La hipocitraturia varía entre un $24-63 \%$ en las cirugías malabsortivas tipo en BGYR. El citrato es la disociación del ácido cítrico, un ácido débil, el estado ácido base es crítico para la excreción del mismo. La 
acidosis conduce a un incremento de la utilización de citrato mitocondrial, así aumenta la reabsorción del citrato renal y disminuye su excreción urinaria. El citrato es un importante inhibidor de la precipitación de oxalato de calcio y fosfato, disminuyendo la cristalización. En las cirugías malabsortivas se observa una reducción del volumen urinario por la disminución de la ingesta de líquidos, y una reducción del $\mathrm{pH}$ favorece la precipitación, cristalización y formación de litiasis ${ }^{10}$. También es importante mantener niveles adecuados de magnesio; aproximadamente el $40 \%$ del magnesio ingerido es absorbido en el intestino delgado y por su condición química (catión divalente con coordinación de seis) aumenta la solubilidad del calcio cuando éste forma complejos con aniones como el fosfato y el oxalato, además de su función en la regulación de PTH.

\section{Déficit de vitamina $\mathrm{D}$ y alteraciones óseas}

El déficit de vitamina $D(V D)$ es muy frecuente en el paciente obeso con una prevalencia que varía entre 13 a $91 \%$. Las posibles causas son la menor exposición a la luz solar (sedentarismo), menor ingesta de alimentos que contiene VD (alimentación saludable), menor capacidad de la piel para liberar vitamina $\mathrm{D}$ la cual, por su condición de hormona liposoluble, tendría un mayor secuestro en tejido adiposo. También se postula una menor 25-hidroxilación en hígado, sobre todo en los pacientes con enfermedad hepática y menor 1-hidroxilación en aquellos pacientes con ERC ${ }^{11,12}$.

El déficit de VD en los pacientes con cirugías malabsortivas (BGYR) llega al 92\% y solo el 13\% presenta niveles óptimos de VD a 10 años de la cirugía. El déficit es multifactorial, la deficiencia prequirúrgica es una de las principales causas; sumado a esto, no solo la deficiencia de sales biliares favorece la malabsorción de la VD sino que el sobrecrecimiento bacteriano en duodeno e ileón proximal impide la correcta absorción de la misma. A esto se agrega la falta de adhesión a tomar suplementos vitamínicos ${ }^{11,12}$.

El déficit de VD favorece el aumento de la PTH que a su vez incrementa la reabsorción de calcio a nivel túbulo contorneado distal, la resorción ósea e indirectamente la absorción de calcio intestinal, lo cual conllevaría a un riesgo de nefrolitiasis y osteoporosis.

Por otra parte, la obesidad ha sido considerada un factor protector contra la enfermedad ósea y si bien un mayor IMC se asocia a una mayor densidad ósea, como se detalló anteriormente, el paciente con obesidad presenta déficit de VD que favorece el hiperparatiroidismo secundario, lo cual se agrava con la $\mathrm{CB}^{13}$. Axelsson et al. ${ }^{14}$ analizaron los datos del registro sueco y hallaron que durante un seguimiento de 3,1 $(1,7-4,6)$ años hubo un mayor riesgo de fracturas en pacientes con y sin DM que realizaron CB (HR 1,26, IC95\% 1,05-1,53 y HR 1,32, IC95\% 1,18-1,47, respectivamente).

Los mecanismos del riesgo de fractura inducida por la CB aún se desconocen, pero las explicaciones más comúnmente sugeridas son la descarga mecánica debida a la pérdida de peso y el hiperparatiroidismo secundario por la deficiencia de vitamina $D$, mientras que las alteraciones hormonales gastrointestinales y su relación con el hueso son más contradictorias.

La carga mecánica, en condiciones fisiológicas normales, participa como regulador principal para mantener la masa y resistencia ósea, y el tamaño del hueso. El mecanismo molecular subyacente de la descarga esquelética se ha relacionado con un up regulation del ARNm de la esclerostina (SOST). La esclerostina es una proteína producida principalmente por osteocitos que poseen mecanorreceptores que convierten las señales mecánicas en señales biológicas. Su función es inhibir la diferenciación y función de las células osteoblásticas al inhibir la Wnt/beta-catenina. Además, la esclerostina estimula la diferenciación y la actividad osteoclástica mediada por el activador del receptor del factor nuclear kappa B (RANKL) y la inhibición de la osteoprotegerina (OPG). De esta manera, la disminución de la carga debido al descenso de peso pos-CB desinhibe a esclerotina y favorece un incremento de la resorción ósea. Esto se demostró clínicamente en un estudio de 90 mujeres premenopáusicas después de los procedimientos de BGYR y banda gástrica (BG). Este estudio señaló un aumento rápido y sostenido del nivel de esclerostina asociado con el incremento de los marcadores de recambio óseo y la caída de la densidad mineral ósea (DMO) en esta población ${ }^{15}$.

\section{Control posquirúrgico}

Existen medidas para reducir los riesgos de nefrolitiasis por CB malabsortiva. En la Tabla 1 se muestran las estrategias y posibles soluciones. Asimismo, es importante conocer los alimentos que contienen alto contenido de oxalato como nueces, almendras, papas fritas, galletitas de chocolate, cítricos, fruta enlatada, higos secos, arándanos, espinaca, espárragos o salsa de tomate, entre otros ${ }^{6,16}$.

Con respecto al metabolismo fosfocálcico, se re- 
comienda control previo a la CB: calcio, fósforo, magnesio, VD y PTH; en caso que la VD se encuentre deficiente o insuficiente se deberá suplementar para logar niveles de VD: $30 \mathrm{ng} / \mathrm{ml}$ y luego pos-CB controlar VD, calcio, fósforo y magnesio seis, 12,18 y 24 meses, y luego anualmente. Reemplazar de ser necesario.
La hiperoxaluria y la nefrolitiasis son complicaciones de las CB malabsortivas con la característica que aumenta su incidencia a largo plazo. El daño sobre el metabolismo fosfocálcico también es a largo plazo. Conocer dichas complicaciones y su mecanismo permite prevenirlas.

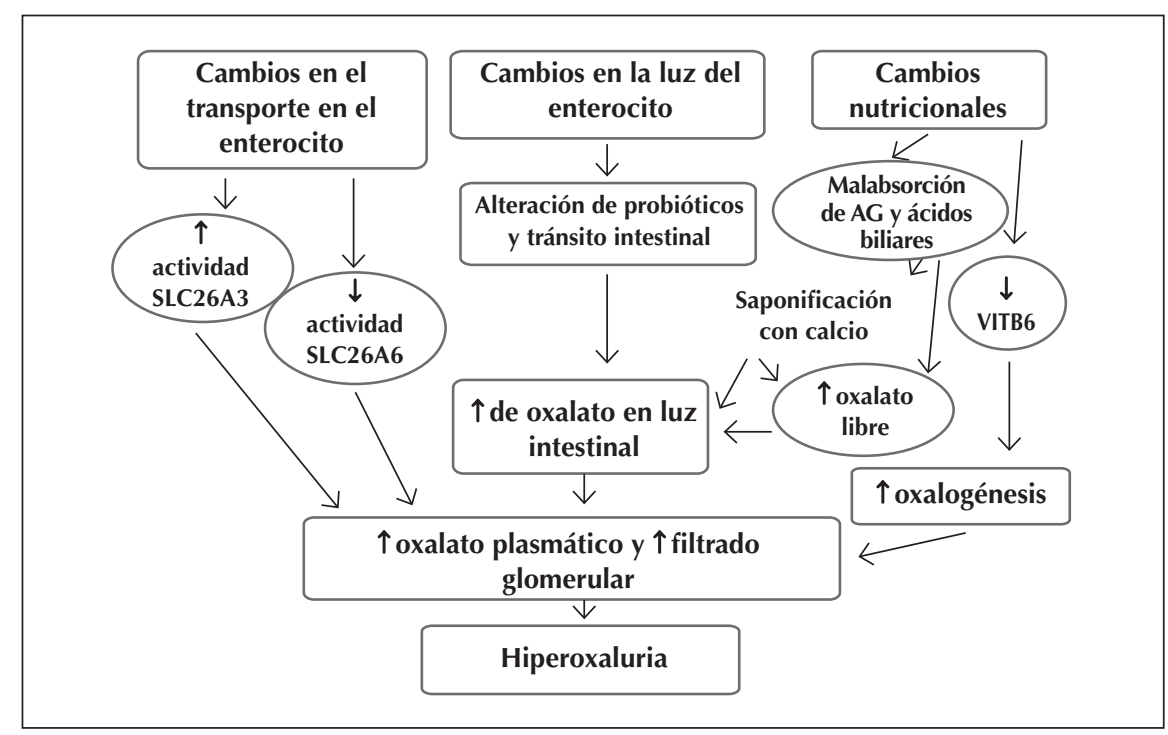

Adaptado de: Canales et al. ${ }^{6}$.

AG: ácidos grasos.

Figura 1: Esquema de los mecanismos involucrados en la hiperoxaluria en las cirugías malabsortivas.

\begin{tabular}{|c|c|}
\hline Estrategias & Soluciones \\
\hline - Diuresis $>2$ litros & $\begin{array}{l}\text { - Incremento de líquidos en pequeñas porciones con alto contenido de } \\
\text { citratos (limonadas) }\end{array}$ \\
\hline - Dieta con bajo contenido de grasas ( $<25 \%$ calorías/día) & - Informar y educar al paciente \\
\hline - Dieta con bajo contenido de oxalatos (80-100 mg/día) para hiperoxalurias & - Informar y educar al paciente \\
\hline - Dieta con bajo contenido de sal (<2.300 mg/día) & - Informar y educar al paciente, similar a paciente con hipertensión \\
\hline - Citrato de potasio para hipocitraturia & - En forma de sellos o comprimidos \\
\hline $\begin{array}{l}\text { - Dieta con alto contenido de calcio } 1000 \mathrm{mg} / \text { día preferentemente citrato } \\
\text { de calcio }\end{array}$ & $\begin{array}{l}\text { - Informar y educar al paciente y/o citrato de calcio } 250 \text { mg/en cuatro } \\
\text { tomas al día }\end{array}$ \\
\hline - Probióticos en hiperoxalutias & - En los yogures que contienen calcio, proteínas y probióticos (experimental) \\
\hline - Niveles adecuados de magnesio & - En caso de deficiencia, citrato de magnesio 300 mg/día (comprimidos) \\
\hline
\end{tabular}

Ben-Porat et al. ${ }^{16}$.

Tabla 1: Estrategias y soluciones para reducir el riesgo de litiasis de oxalato de calcio luego de CB malabsortiva.

\section{BIBLIOGRAFÍA}

1. Liakopoulos V, Franzén S Svensson AM, et al. Pros and cons of gastric bypass surgery in individuals with obesity and type 2 diabetes: nationwide, matched, observational cohort study. BMJ Open 2019 Jan 15; 9(1):e023882. DOI: 10.1136/bmjopen-2018-023882.

2. Rariy $\mathrm{CHM}$, Rometo D, Korytkowski M. Post-gastric bypass hypoglycemia. Curr Diab Rep 2016 Feb;16(2):19. DOI: 10.1007/ s11892-015-0711-5.

3. Martin WP, Docherty NG. Le Roux CW. Impact of bariatric surgery on cardiovascular and renal complications of diabetes: a focus on clinical outcomes and putative mechanisms. Expert Rev Endocrinol Metab 2018; 13(5):251-262.
4. Shulman A, Peltonen M, Sjöström CD, et al. Incidence of end-stage renal disease following bariatric surgery in the Swedish Obese Subjects Study. Int J Obes (Lond) 2018; 42(5): 964-973.

5. Cohen JB, Tewksbury CM, Torres Landa S, et al. National postoperative bariatric surgery outcomes in patients with chronic kidney disease and end-stage kidney disease. Obes Surg 2019; 29(3):975-982.

6. Canales BK, Hatch M. Kidney stone incidence and metabolic urinary changes after modern bariatric surgery: review of clinical studies, experimental models, and prevention strategies. Surg Obes Relat Dis 2014; 10(4):734-742.

7. Upala S, Jaruvongvanich V, Sanguankeo A. Risk of nephrolithiasis, hyperoxaluria, and calcium oxalate supersaturation increased after Roux-en-Y gastric bypass surgery: a systematic review and meta-analysis. Surg Obes Relat Dis 2016; 12(8):1513-1521. 
8. Thongprayoon $\mathrm{C}$, Cheungpasitporn $\mathrm{W}$, Vijayvargiya $\mathrm{P}$, et al The risk of kidney stones following bariatric surgery: a systematic review and meta-analysis. Ren Fail 2016; 38(3):424-430.

9. Bhatti UH, Duffy AJ, Roberts KE, et al. Nephrolithiasis after bariatric surgery: a review of pathophysiologic mechanisms and procedural risk. Int J Surg 2016; 36(Pt D):618-623.

10. Maalouf NM, Tondapu P Guth, ES, et al. Hypocitraturia and hyperoxaluria after Roux-en-Y gastric bypass surgery. J Urol 2010; 183(3):1026-1030.

11. Chakhtoura M, Rahme M, El-Hajj Fuleihan G. Vitamin D metabolism in bariatric surgery. Endocrinol Metab Clin N Am 2017; 46:947-982.
12. Lespessailles $\mathrm{E}$, Toumi H. Vitamin D alteration associated with obesity and bariatric surgery. Exp Biol Med 2017; 242(10): 1086-1094.

13. Gregory NS. The effects of bariatric surgery on bone metabolism. Endocrinol Metab Clin N Am 2017; 46(1):105-116.

14. Axelsson $\mathrm{KF}$, Werling $\mathrm{M}$, Eliasson $\mathrm{B}$, et al. Fracture risk after gastric bypass surgery. A retrospective cohort study. J Bone Miner Res 2018; 33(12):2122-2131.

15. Sakhaee K, Poindexter J, Aguirre C. The effects of bariatric surgery on bone and nephrolithiasis. Bone 2016; 84:1-8.

16. Ben- Porat $T$, Weiss-Sadan A, Rottenstreich $A$, et al. Nutritional management for chronic kidney disease patients who undergo bariatric surgery: a narrative review. Adv Nutr 2019; 10:122-132.

\section{Remisión, recurrencia de la DM y/o la ERC luego de la CB. Factores predictores}

\section{CB y remisión-recurrencia de la DM2}

Un grupo de expertos se reunió para tratar de definir los siguientes términos que hacen a la interpretación de los resultados de las intervenciones y elaborar recomendaciones ${ }^{1}$.

- Remisión: lograr una glucemia por debajo del rango no diabético en ausencia de tratamiento farmacológico o procedimientos en curso, tales como reemplazos repetidos de dispositivos endoluminales.

- Remisión parcial: al menos un año.

- HbA1c: <6,5\%.

- Glucemia en ayunas: entre 100 y 125 mg/dl.

- Remisión completa: al menos un año.

- HbA1c: $<5,6 \%$.

- Glucemias en ayunas: <100 mg/dl.

- Remisión prolongada: remisión completa que dura más de cinco años y podría considerarse una cura.

Diferentes estudios demostraron que los pacientes obesos con IMC $\geq 35$ con antecedentes de DM2 de cinco o más años de diagnóstico y $\mathrm{HbA} 1 \mathrm{c} \geq 7 \%$ sometidos a $\mathrm{CB}$, era más probable que remitieran su DM a los dos años, comparados con quienes recibieron tratamiento médico solamente. A los cinco años, en aproximadamente la mitad de los pacientes hubo recurrencia de la DM, sin embargo, la proporción de pacientes libres de DM a los cinco años fue mayor en $\mathrm{CB}$ que en tratamiento médico $(50 \mathrm{vs} 0 \%)^{2,3}$.

\section{CB y remisión-recurrencia de la ERC}

Hay evidencia que aún en los pacientes con recurrencia de DM, los períodos transitorios de mejoría del control pueden otorgar beneficios sobre las complicaciones crónicas microvasculares. Este efecto beneficioso se denomina legacy o memoria metabólica ${ }^{4}$.
En un estudio retrospectivo, los pacientes que remitieron la DM después de la CB tuvieron un $29 \%$ de reducción del riesgo de desarrollar complicaciones microvasculares y por cada año adicional en remisión, el riesgo de complicación microvascular se redujo un 19\% comparado con los que nunca remitieron. Esto confirmaría el efecto legacy ${ }^{5}$.

Chang et al. ${ }^{6}$ compararon el riesgo de disminución del FG a menos del 30\% o mayor, o la duplicación de la creatinina o enfermedad renal terminal (ERT), en 985 pacientes sometidos CB, con 985 controles apareados. El FG en la línea de base fue de $<90 \mathrm{ml} / \mathrm{min} / 1,73 \mathrm{~m}^{2}$. El 36\% tenía DM2 y el $2 \%$ DM1. La pérdida de peso al año fue de $40,4 \mathrm{Kg}$ en el grupo operado y 1,4 Kg en la cohorte control. El tiempo medio de seguimiento fue de 4,4 años. En el análisis ajustado, a quienes se les realizó CB presentaron una disminución significativa del riesgo de reducción del $\mathrm{FG}$ del $30 \%$ o más (HR 0,42, IC: 0,26-0,71) comparados con la cohorte apareada. Concluyeron que la CB puede ser una opción para prevenir el deterioro de la función renal en individuos severamente obesos.

Shulman et al. ${ }^{7}$ publicaron un estudio no randomizado, apareado, de intervención y prospectivo de sujetos obesos suecos (SOS), comparando los efectos de la CB a largo plazo vs tratamiento convencional de obesidad, sobre la incidencia de ERT y enfermedad renal crónica estadio 4 (ERC E4). Los resultados mostraron que la incidencia a largo plazo de ERT se redujo en un $70 \%$ y la incidencia de ERC E4/ERT en un 65\%, respectivamente, en el grupo de cirugía comparado con el grupo control, demostrando la importancia de la pérdida de peso como estrategia de prevención a largo plazo de la enfermedad renal. La hiperinsulinemia y la macroabuminuria al ingreso predijeron beneficios relativos de la CB comparados con el tratamiento convencional de la obesidad. Concluyeron que la CB se asoció con una protección a largo plazo contra la ERT y ERC E4/ERT. 
Asimismo, Heneghan et al. ${ }^{8}$ identificaron pacientes con DM2 y CB con cinco años de seguimiento y analizaron remisión, mejoría o sin cambios en el índice albumina/creatinina. La nefropatía diabética (microalbuminuria 30 a 300 mg/g o macroalbuminuria $>300 \mathrm{mg} / \mathrm{g}$ ) estaba presente en el $37,6 \%$ en el preoperatorio y mejoró en el $58,3 \%$, con un seguimiento medio de 66 meses. Entre los que no tenían nefropatía diabética pre-CB, se desarrolló albuminuria a los cinco años solo en el $25 \%$. La remisión a los cinco años y mejoría de la DM fue del 44 y 33\% respectivamente. La conclusión de este estudio fue que la CB puede inducir una significativa y sostenible mejoría de la DM2 y mejorar el desarrollo de las complicaciones microvasculares como la nefropatía.

Otros estudios concluyeron que la CB, especialmente bypass en Y de Roux (BPYR), tuvo significativa mejoría por hasta tres años en el FG estimado en pacientes con ERC E3-4 y albuminuria9,10.

Por otra parte, Holcomb et al. ${ }^{11}$ hallaron una mejoría en el FG independiente del porcentaje de pérdida de peso que sugiere un mecanismo alternativo para la mejoría de la función renal, además de la pérdida de peso sola.

\section{Predicción de remisión de la DM después de la CB}

La CM se asocia a algún riesgo de complicaciones, por ello es importante predecir qué pacientes responderán a la cirugía y tendrán remisión de la DM. Para ello se propusieron varios sistemas de valoración para la selección de los pacientes con DM2 posibles de ser candidatos para cirugía de bypass gástrico.

Existen varias escalas (scores) y modelos matemáticos para la predicción de la remisión de la DM2 luego de la CB. Hasta la fecha existen tres tipos de valoraciones: ABCD, DiaRem y Diabetes Remission Score (DRS).

La escala ABCD incluye edad, IMC, nivel de péptido $\mathrm{C}$ y duración de la DM; la escala de DiaRem comprende edad, HbA1c, medicación antidiabética y el uso de insulina; por último, la escala DRS consta de siete variables: edad, IMC, duración de la DM2, complicaciones microvasculares, complicaciones macrovasculares, uso de insulina preoperatoria y péptido $\mathrm{C}$ estimulado.

En 2017 se publicó la escala Individualized Metabolic Surgery Score (IMS) con la cual se estudió la cohorte más grande hasta la fecha $(n=900)$ con un seguimiento posoperatorio medio de siete años, y se encontró remisión de DM en el 49\% con bypass y $28 \%$ con manga $(p<0,001)$. Los cuatro predictores independientes de remisión a largo plazo fueron: duración de la DM2 preoperatoria $(p<0,0001)$, número de la medicación antidiabética preoperatoria $(p<0,0001)$, uso de insulina $(p=0,002)$ y control glucémico $(\mathrm{HbA} 1 \mathrm{c}<\mathrm{a} 7 \%)(\mathrm{p}=0,002)^{12}$.

Al comparar los tres sistemas de valoración, Ahuja et al. ${ }^{13}$ encontraron que, al año de la cirugía, comparando por área bajo la curva por medio de la curva ROC, los tres sistemas de valoración no mostraron diferencias estadísticamente significativas entre ellos. Por análisis multivariado, los factores significativamente asociados a la remisión de la DM fueron su duración, el péptido C y la $\mathrm{HbA} 1 \mathrm{c}$ preoperatoria. Aunque la escala DiaRem tiene máxima área bajo la curva y la mejor sensibilidad y especificidad, no hubo diferencias estadísticamente significativas en cuanto a predicción de remisión de $\mathrm{DM}^{13}$.

\section{Recomendaciones}

- Es importante predecir qué pacientes responderán a la cirugía bariátrica y tendrán remisión de DM.

- En la remisión parcial o completa de menos de cinco años de duración debe realizarse screening de las complicaciones crónicas de la DM con la frecuencia habitual.

- Si la remisión completa excede los cinco años, podría hacerse el screening menos frecuentemente (según el estado de cada complicación).

\section{BIBLIOGRAFÍA}

1. Buse JB, Caprio S, Cefalu WT, et al. How do we define cure of diabetes? Consensus Statement. Diabetes Care 2009; 32(11):2133-2135.

2. Mingrone G, Panunzi S, De Gaetano A, et al. Bariatric surgery versus conventional medical therapy for type 2 diabetes. N Engl J Med 2012; 366:1577-1585.

3. Mingrone G, Panunzi S, De Gaetano A, et al. Bariatric-metabolic surgery versus conventional medical treatment in obese patients with type 2 diabetes: 5 year follow-up of an openlabel, single-centre, randomised controlled trial. Lancet 2015; 386(9997):964-73.

4. Fisher DP, Johnson E, Haneuse S, et al. Association between bariatric surgery and macrovascular disease outcomes in patients with type 2 diabetes and severe obesity. JAMA 2018; 320(15):1570-1582.

5. Coleman KJ, Haneuse S, Johnson E, et al. Long-term microvascular disease outcomes in patients with type 2 diabetes after bariatric surgery: evidence for the legacy effect of surgery. Diabetes Care 2016; 39(8):1400-7. 
6. Chang AR, ChenY, Still $C$, et al. Bariatric surgery is associated with improvement in kidney outcomes. Kidney Int 2016; 90(1):164-71.

7. Shulman A, Peltonen M, Sjöström CD, et al. Incidence of end-stage renal disease following bariatric surgery in the Swedish Obese Subjects Study. Int J Obes (Lond) 2018; 42(5):964-973.

8. Heneghan HM, Cetin D, Navaneethan SD, et al. Effects of bariatric surgery on diabetic nephropathy after 5 years of follow-up. Surg Obes Relat Dis 2013; 9(1):7-14.

9. Imam $\mathrm{TH}, \mathrm{MD}$, Fischer $\mathrm{H}$, et al. Estimated GFR before and after bariatric surgery in CKD. Am J Kidney Dis 2017; 69(3):380-388.
10. Li K, Zou J,Ye Z, et al. Effects of bariatric surgery on renal function in obese patients: a systematic review and meta-analysis. PLoS One 2016; 11(10):e0163907.

11. Holcomb CN, Goss LE, et al. Bariatric surgery is associated with renal function improvement. Surg Endosc 2018; 32(7):276-281.

12. Aminian A, Brethauer SA, Andalib A, et al. Individualized metabolic surgery score: Procedure selection based on diabetes severity. Ann Surg 2017; 266(4):650-657.

13. Ahuja $A$, Tantia $O$, Chaudhuri $T$, et al. Predicting remission of diabetes post metabolic surgery: a comparison of ABCD, DiaRem, and DRS scores. Obes Surg 2018; 28(7):2025-2031. 